Review

\title{
Clinical Application of Radiolabeled RGD Peptides for PET Imaging of Integrin $\alpha_{v} \beta_{3}$
}

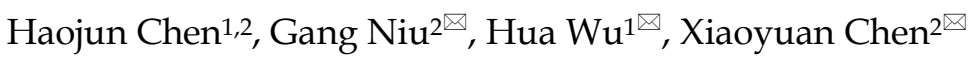 \\ 1. Department of Nuclear Medicine, Xiamen Cancer Center, the First Affiliated Hospital of Xiamen University, Xiamen, China \\ 2. Laboratory of Molecular Imaging and Nanomedicine, National Institute of Biomedical Imaging and Bioengineering, National Institutes of Health, Bethesda, \\ Maryland \\ $\triangle$ Corresponding authors: Gang Niu (niug@mail.nih.gov); Hua Wu (wuhua1025@163.com); Xiaoyuan Chen (shawn.chen@nih.gov)
}

(C) Ivyspring International Publisher. Reproduction is permitted for personal, noncommercial use, provided that the article is in whole, unmodified, and properly cited. See http://ivyspring.com/terms for terms and conditions.

Received: 2015.07.14; Accepted: 2015.10.06; Published: 2016.01.01

\begin{abstract}
Molecular imaging for non-invasive assessment of angiogenesisis is of great interest for clinicians because of the wide-spread application of anti-angiogenic cancer therapeutics. Besides, many other interventions that involve the change of blood vessel/tumor microenvironment would also benefit from such imaging strategies. Of the imaging techniques that target angiogenesis, radiolabeled Arg-Gly-Asp (RGD) peptides have been a major focus because of their high affinity and selectivity for integrin $\alpha_{v} \beta_{3}$--one of the most extensively examined target of angiogenesis. Since the level of integrin $\alpha_{v} \beta_{3}$ expression has been established as a surrogate marker of angiogenic activity, imaging $\alpha_{v} \beta_{3}$ expression can potentially be used as an early indicator of effectiveness of antiangiogenic therapy at the molecular level. In this review, we summarize RGD-based PET tracers that have already been used in clinical trials and intercompared them in terms of radiosynthesis, dosimetry, pharmacokinetics and clinical applications. A perspective of their future use in the clinic is also provided.
\end{abstract}

Key words: Angiogenesis, RGD, PET, clinical translation

\section{Introduction}

Tumor angiogenesis is the process of forming new blood vessels from preexisting vasculatures, which has been well recognized as an essential hallmark for tumor growth, invasion and metastasis [1]. Without the neovasculature to transport oxygen and nutrients, solid tumors cannot grow beyond 1-2 mm in size [2]. Once vascularized, the tumor begins to grow rapidly. The angiogenic process depends on migration and invasion of vascular endothelial cells and is mainly regulated by vascular endothelial growth factor receptors (VEGFRs) and cell adhesion receptor integrins [3].

Integrins, which contain two noncovalently bound transmembrane subunits ( $\alpha$ and $\beta$ subunits), are the bridges for cell-cell and cell-extracellular matrix (ECM) interactions [4]. Integrins play very important roles in tumor angiogenesis and metastasis [5]. Several integrins, especially integrin $\alpha_{v} \beta_{3}$, are sig- nificantly up-regulated on activated endothelial cells during angiogenesis but not on quiescent endothelial cells $[6,7]$. Therefore, integrin $\alpha_{v} \beta_{3}$ represents a potential molecular marker for angiogenesis during imaging and therapy [4].

Majority of integrin-targeted imaging tracers are based on the tripeptide Arg-Gly-Asp (RGD) acid sequence because of its high affinity and specificity for integrin $\alpha_{v} \beta_{3}$. These tracers were developed for various imaging strategies, including positron emission tomography (PET), single photon emission computed tomography (SPECT), molecular magnetic resonance imaging (mMRI), optical fluorescence, optical bioluminescence, photoacoustic, and targeted contrast-enhanced ultrasound [8-13]. Although the spatial and temporal resolutions of PET may not be as impressive as some other imaging modalities, its specificity and sensitivity are exquisite [14]. Moreo- 
ver, quantitative analysis is relatively easy to accomplish with PET data. Therefore, several RGD peptide based PET tracers have been investigated for clinical translation including $\left[{ }^{18} \mathrm{~F}\right]$ Galacto-RGD, $\left[{ }^{18} \mathrm{~F}\right]$ Fluciclatide, [ $\left.{ }^{18} \mathrm{~F}\right]$ RGD-K5, [ $\left.{ }^{18} \mathrm{~F}\right] \mathrm{FPPRGD} 2, \quad\left[{ }^{18} \mathrm{~F}\right]$ Alfatide, $\left[{ }^{68} \mathrm{Ga}\right] N O T A-R G D$ and $\left[{ }^{68} \mathrm{Ga}\right]$ NOTA-PRGD2. In this review, we focus on these clinically available RGD-based PET tracers and intercompare them in terms of radiosynthesis, dosimetry, pharmacokinetics and clinical efficacy. We also noticed that several ${ }^{99 \mathrm{~m} T c-}$ and ${ }^{111} \mathrm{In}$-labeled RGD peptide tracers have been used in clinical investigations. Due to the lack of direct comparison between SPECT and PET, these non-PET tracers are not included for discussion.

\section{Radiosynthesis}

For radionuclide imaging, strategies in radiotracer design and synthesis are required to decrease the barriers involved in radiochemistry and allow more researchers and clinicians to pursue preclinical investigation or clinical practice [15]. The RGD peptides have been successfully radiolabeled with ${ }^{18} \mathrm{~F}$

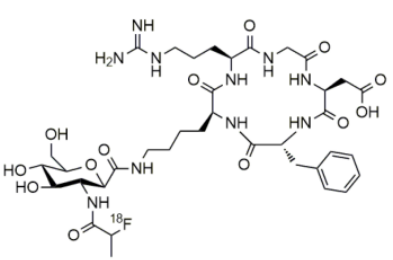

$\left[{ }^{18} \mathrm{~F}\right]$ Galacto-RGD

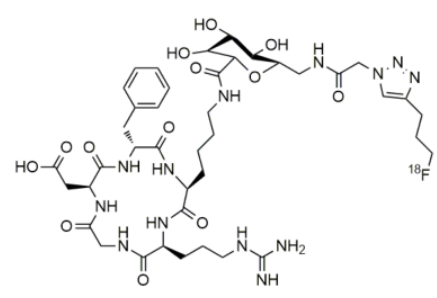

$\left[{ }^{18} \mathrm{~F}\right]$ RGD-K5

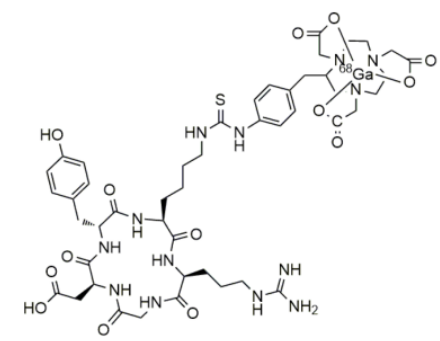

$\left[{ }^{68}\right.$ Ga]NOTA-RGD

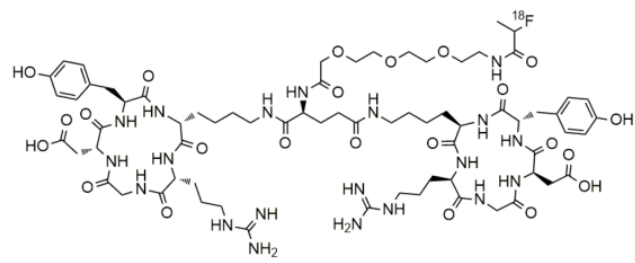

$\left[{ }^{18}\right.$ F]FPPRGD2 and ${ }^{68} \mathrm{Ga}$ via different routes of chemistry and radiochemistry (Figure 1). The radiolabeling stategies of these compounds are summarized in Table 1.

$\left.{ }^{[18} \mathrm{F}\right]$ Galacto-RGD was the first RGD PET tracer tested in human subjects [16]. This compound was designed by conjugating a sugar amino acid to the cyclic peptide c(RGDfK) [17]. Radiolabeling of the glycopeptide was performed via acylation of the amino methyl group at the C1-position of the sugar moiety using 4-nitrophenyl-2-[18F]fluoropropionate. The whole radiolabeling process requires 4 steps of radiosynthesis and 3 rounds of HPLC purification. Final HPLC with a semi-preparative column obtains $\left[{ }^{18} \mathrm{~F}\right]$ Galacto-RGD with specific activities ranging between 40 and $100 \mathrm{GBq} / \mu \mathrm{mol}$ and radiochemical purity over $98 \%$. The total synthesis time was about 200 $\pm 18 \mathrm{~min}$ (including final HPLC purification) with radiochemical yield of $29.5 \pm 5.1 \%$ (decay corrected). According to Beer et al. [18], starting with 2,200 MBq of $\left[{ }^{18} \mathrm{~F}\right] \mathrm{F}^{-}, 185 \mathrm{MBq}$ of $\left[{ }^{18} \mathrm{~F}\right]$ Galacto-RGD could be prepared.

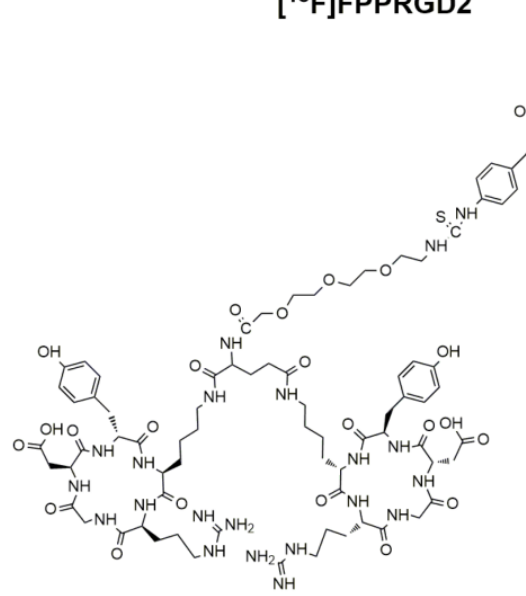

$\left[{ }^{68} \mathrm{Ga}\right]$ NOTA-PRGD2

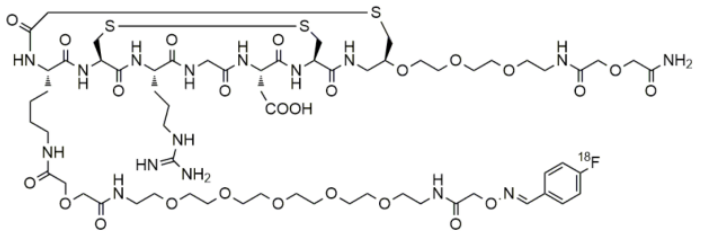

$\left[{ }^{18} \mathrm{~F}\right]$ Fluciclatide

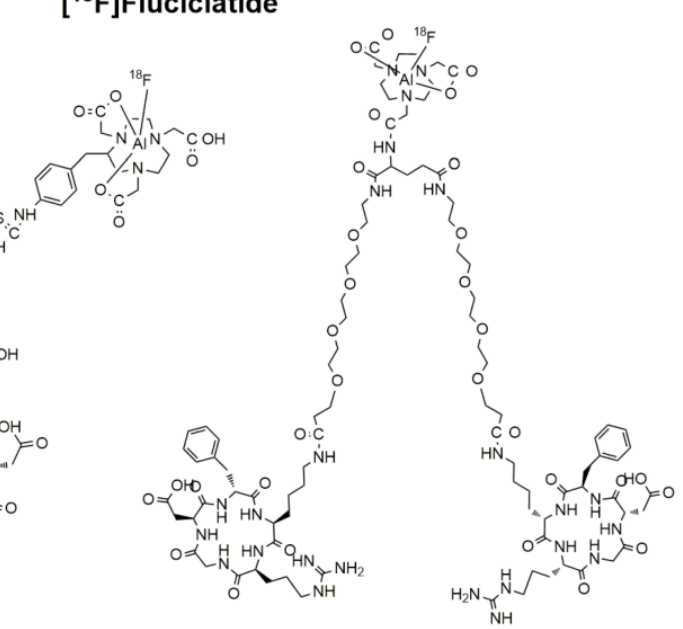

$\left[{ }^{18} \mathrm{~F}\right]$ Alfatide II

Figure 1.Chemical structures of clinically available RGD-based PET tracers. 
Table 1.Radiosynthesis and dosimetry of clinically available RGD-based PET Tracers

\begin{tabular}{|c|c|c|c|c|c|c|}
\hline Compound & $\begin{array}{l}\text { Synthesis time } \\
\text { (min) }\end{array}$ & $\begin{array}{l}\text { HPLC } \\
\text { needed }\end{array}$ & $\begin{array}{l}\text { Specific activity } \\
(\mathrm{GBq} / \mu \mathrm{mol})\end{array}$ & Radiochemical yield (\%) & $\begin{array}{l}\text { Effective dose } \\
(\mu \mathrm{Sv} / \mathrm{MBq})\end{array}$ & Ref \\
\hline$\left[{ }^{18} \mathrm{~F}\right]$ Galacto-RGD & $200 \pm 18$ & Yes & $40-100$ & $29.5 \pm 5.1$ & $\begin{array}{l}17, \text { male } \\
20, \text { female }\end{array}$ & {$[17,18]$} \\
\hline$\left[{ }^{18} \mathrm{~F}\right]$ Fluciclatide & 170 & Yes & $0.07-0.16$ & $23.0 \pm 5.0$ & 26 & [19] \\
\hline$\left[{ }^{18} \mathrm{~F}\right] \mathrm{RGD}-\mathrm{K} 5$ & 90 & Yes & 14.8 & $10-20$ & 15 & {$[20,21]$} \\
\hline$\left[{ }^{18} \mathrm{~F}\right] \mathrm{FPPRGD} 2$ & 180 & Yes & $44.4 \pm 26.4$ & $10-15$ & 39.6 & {$[22]$} \\
\hline$\left[{ }^{18} \mathrm{~F}\right]$ Alfatide & 20 & No & 37 & $42.1 \pm 2.0$ & 17.0 & {$[25,26]$} \\
\hline [18F]Alfatide II & 20 & No & $14.8-37$ & $40-60$ & 17.0 & [29] \\
\hline [68Ga]NOTA-RGD & 30 & Yes & 17.4 & 89 & -- & {$[30]$} \\
\hline [68Ga]NOTA-RGD & 15 & No & 74 & 98 & 25.0 & [31] \\
\hline$\left.{ }^{68} \mathrm{Ga}\right] N O T A-P R G D 2$ & 30 & Yes & -- & 70 & -- & [25] \\
\hline [68Ga]NOTA-PRGD2 & 15 & No & $9.25-46.25$ & 90 & 22.6 & {$[25,36]$} \\
\hline
\end{tabular}

${ }^{*}$ The radiolabeling procedures of several peptides were performed without HPLC purification (such as ${ }^{18} \mathrm{~F}-\mathrm{Alfatide},{ }^{68 \mathrm{Ga}-N O T A-R G D}$, ${ }^{68} \mathrm{Ga}-\mathrm{NOTA}$-PRGD2), and the specific activity is strongly dependent on the activity used for the synthesis.

[18F]Fluciclatide, also known as [18F]AH11185, was developed by GE Healthcare with a core peptide sequence of ACDRGDCFCG. The compound was optimized by the cyclization and introduction of two disulfide bonds to stabilize the molecule with minimal disruption of the RGD pharmacophore. In contrast to Galacto-RGD, fluciclatide shows highest binding affinity for integrin $\mathrm{a}_{\mathrm{v}} \beta_{5}\left(\mathrm{IC}_{50} 0.1 \mathrm{nM}\right)$, followed by integrin $\alpha_{v} \beta_{3}\left(\mathrm{IC}_{50} 11.1 \mathrm{nM}\right)$. Radiosynthesis of $\left[{ }^{18} \mathrm{~F}\right]$ Fluciclatide was performed on an automated module (TRACERlab FX F-N; GE Healthcare) by coupling an aminooxy-functionalized precursor of Fluciclatide with $4-\left[{ }^{18} \mathrm{~F}\right]-$ fluorobenzaldehyde at $\mathrm{pH}$ 3.5 to form the oxime $\left.{ }^{18} \mathrm{~F}\right]$ Fluciclatide. The whole procedure involves two reaction pots and two steps of HPLC purification, the reaction time was around 170 min. The specific activity of $\left.{ }^{[18} \mathrm{F}\right]$ Fluciclatide, determined by HPLC, ranging from 76-170 GBq/mmol, which is substantially less than that of [18F]Galacto-RGD [19].

$\left[{ }^{18} \mathrm{~F}\right]$ RGD-K5 was developed by Siemens Molecular Imaging Inc. Synthesis of [ $\left.{ }^{18} \mathrm{~F}\right] \mathrm{RGD}-\mathrm{K} 5$ was accomplished on an Explora RN automated synthesis module with average yields of $10-20 \%$ (decay corrected) and average synthesis time of $90 \mathrm{~min}$ [20]. Briefly, pentyne tosylate was reacted with $\mathrm{K}^{18} \mathrm{~F}$ in the presence of Kryptofix 222, $\mathrm{K}_{2} \mathrm{CO}_{3}$ and acetonitrile $(\mathrm{MeCN})$ at $110{ }^{\circ} \mathrm{C}$ followed by distillation and clicking with RGD-K5-N $\mathrm{N}_{3}$ in the presence of alcohol (EtOH) and water. $\left.{ }^{18} \mathrm{~F}\right]$ RGD-K5 was purified by RP-HPLC (MeCN: water with $0.05 \%$ TFA) and reconstituted in 10\% EtOH:Water via $\mathrm{C}_{18}$ trap and release. The specific activity of $\left.{ }^{18} \mathrm{~F}\right] \mathrm{RGD}-\mathrm{K} 5$ was calculated to be at least $14.8 \mathrm{GBq} / \mu \mathrm{mol}$ [21]. Since RGD K5 is prepared by click chemistry, it may be suitable for (semi) automated synthesis.

[18F]FPPRGD2, based on a PEGylated dimeric RGD peptide ( $\left.\mathrm{PEG}_{3}-\mathrm{Glu}[\mathrm{c}(\mathrm{RGDyK})]_{2}\right)$, was the first dimeric RGD peptide approved by the Food and Drug Administration as an exploratory investigative new drug (IND 104150) to test in human. Regarding its radiosynthesis, 4-nitrophenyl-2-[ $\left.{ }^{18} \mathrm{~F}\right]$ fluoropropionate $\left(\left[{ }^{18} \mathrm{~F}\right] \mathrm{NPE}\right)$ was produced first by means of nucleophilic ${ }^{18} \mathrm{~F}$ fluorination of methyl 2-bromo propionate, hydrolysis, and esterification at one-pot synthesis performed with a GE TRACERlab $\mathrm{FX}_{\mathrm{FN}}$ synthesizer. Subsequently, the conjugation between $\left[{ }^{18} \mathrm{~F}\right] \mathrm{NPE}$ and the RGD dimer was performed in a customized module to yield $\left[{ }^{18} \mathrm{~F}\right] \mathrm{FPPRGD} 2$ with a specific radioactivity level of $44.4 \pm 26.4 \mathrm{GBq} / \mu \mathrm{mol}$. Starting from $\left[{ }^{18} \mathrm{~F}\right] \mathrm{F}-$, the total synthesis time of [ $\left.{ }^{18} \mathrm{~F}\right] \mathrm{FPPRGD} 2$ was about $180 \mathrm{~min}$ with the radiochemical yield of $10-15 \%$ (decay corrected) [22].

As shown, all these ${ }^{18} \mathrm{~F}$-labeled RGD peptides suffered from multistep, time-consuming and low-yield synthetic procedures. Moreover, it is very challenging to make these radiosynthetic processes fully automatic, which in turn sets a high technical barrier for using these PET probes in the clinical setting. Application of chelation chemistry has led to the discovery and development of $\left[{ }^{18} \mathrm{~F}\right]$ fluoridealuminum complexes to radiolabel peptides [23, 24]. Chen's group has successfully prepared $\left.{ }^{18} \mathrm{~F}\right]$ AlF-NOTA-PRGD2 (donated as $\left[{ }^{18} \mathrm{~F}\right]$ Alfatide). The whole radiosynthesis (including purification) could be accomplished within $40 \mathrm{~min}$ [25]. Under recently introduced kit formulation method, the total time can be reduced to $20 \mathrm{~min}$, with a decay-corrected yield of $42.1 \pm 2.0 \%$ and radiochemical purity of over $95 \%$ [26]. The specific activity of [18F]Alfatide was calculated to be at least $37 \mathrm{GBq} / \mu \mathrm{mol}$.

However, the glutamic acid linked dimeric peptide with a free a-amine is not stable under acidic condition [27], presumably due to the neighboring amine participation in the hydrolysis. Consequently, a much more stable new tracer $\left[{ }^{18} \mathrm{~F}\right]$ NOTA-E[PEG4$\mathrm{c}(\mathrm{RGDfk})]_{2}$ (denoted as Alfatide II) has been developed. Alfatide II can also be radiolabeled using the kit formulation method $[28,29]$, which is pretty similar to Alfatide. The total synthesis time was about $20 \mathrm{~min}$ 
with radiochemical yield of $40-60 \%$ (corrected) and radiochemical purity $>95 \%$. The specific activity was about $14.8-37 \mathrm{GBq} / \mu \mathrm{mol}$ at the end of synthesis based on the amount of peptide used and the amount of radioactivity trapped on the $\mathrm{C}_{18}$ column. Compare with the radiosynthesis of $\left[{ }^{18} \mathrm{~F}\right]$ Galacto-RGD, $\left[{ }^{18} \mathrm{~F}\right]$ Fluciclatide and $\left[{ }^{18} \mathrm{~F}\right] \mathrm{FPPRGD} 2$, this rapid radiofluorination kit provides a strategy to simplify the radiolabeling procedure for RGD peptides.

Besides ${ }^{18} \mathrm{~F},{ }^{68} \mathrm{Ga}$ is another popular positron-emitting radioisotope which can be produced by use of a ${ }^{68} \mathrm{Ge} /{ }^{68} \mathrm{Ga}$ generator. To facilitate ${ }^{68} \mathrm{Ga}$ labeling, NOTA-RGD and NOTA-PRGD2 were produced by coupling SCN-Bz-NOTA to the RGD peptide $c\left(\right.$ RGDyK) or $\mathrm{PEG}_{3}-\mathrm{E}[\mathrm{c}(\mathrm{RGDyK})]_{2}$ over the lysine or $\mathrm{PEG}_{3}-\mathrm{NH}_{2}$ side chain. Labeling with ${ }^{68} \mathrm{Ga}$ was possible by incubation at room temperature for $10 \mathrm{~min}$. This reaction condition is attractive, especially for the labeling of heat-sensitive compounds. For $\left[{ }^{68} \mathrm{Ga}\right.$ ]NOTA-RGD, Kim et al. [30] reported labeling efficiency was around $90 \%$ (uncorrected) with the specific activity of $17.4 \mathrm{GBq} / \mu \mathrm{mol}$ (with HPLC purification). In a later report from the same group, $\left[{ }^{68} \mathrm{Ga}\right]$ NOTA-RGD was synthesized using a minor modification for a clinical study (without HPLC purification) [31]. In this study, the compound could be produced with a reaction time of 5 min followed by Sep-Pak purification, yielding in $>98 \%$ of the product with a specific activity of $74 \mathrm{GBq} /$ umol. Regarding the dimeric RGD compound, the radiolabeling of $\left[{ }^{68} \mathrm{Ga}\right]$ NOTA-PRGD2 was reported by Chen group. With HPLC purification, the radiochemical yield for $\left[{ }^{68} \mathrm{Ga}\right]$ NOTA-PRGD2 was about $70 \%$ (uncorrected) with the specific activity around $9.4 \mathrm{GBq} / \mu \mathrm{mol}$ [25]. To further simplify the labeling procedure, the solid-phase extraction method was used to prepare $\left[{ }^{68} \mathrm{Ga}\right.$ ]NOTA-PRGD2. Through this method, the radi- ochemical yield was $90 \%$ at $80{ }^{\circ} \mathrm{C}$ with radiochemical purity over $95 \%$. The specific activity ranges from 9.25-46.25 GBq/ $\mu \mathrm{mol}$ at the end of synthesis based on the amount of peptide and radioactivity used. As the labeling chemistry of $\left[{ }^{68} \mathrm{Ga}\right] N O T A-R G D /\left[{ }^{68} \mathrm{Ga}\right]$ NOTA-PRGD2 is performed by metal complexation, it is therefore more straightforward and less time-consuming than [ $\left.{ }^{18} \mathrm{~F}\right]$ Galacto-RGD, $\left[{ }^{18} \mathrm{~F}\right]$ Fluciclatide and $\left[{ }^{18} \mathrm{~F}\right] \mathrm{FPPRGD} 2$. Moreover, for the same peptide (such as NOTA-PRGD2), the labeling yield of forming $\left[{ }^{68} \mathrm{Ga}\right.$ ] complex is higher that of forming $\left[{ }^{18} \mathrm{~F}\right] \mathrm{FAl}$ complex, and the amount of peptide needed is also less [25]. Despite the short synthesis time for $\left[{ }^{68} \mathrm{Ga}\right]$-labeled RGD, the short half-life (68 min) makes it difficult for commercial distribution.

\section{Pharmacokinetics}

Although being structurally different, all of clinically investigated RGD peptides, including monomers and dimers, depict very similar in vivo pharmacokinetic properties [21, 26, 32-36]. Tracer uptake of different RGD compounds ([$\left.{ }^{18} \mathrm{~F}\right]$ GalactoRGD, [18F]FPPRGD2, [ $\left.{ }^{18} \mathrm{~F}\right]$ Alfatide and [ $\left.{ }^{68} \mathrm{Ga}\right]$ PRGD2) in normal organs were summarized in Table 2 based on existing clinical data. The biodistribution data showed primary renal route of tracer clearance, with prominent tracer uptake in the kidneys and bladder (Figure 2). Concerning the intense tracer accumulation in the urine, image quality and analysis of lesions that adjacent to the urogenital tract and bladder are impaired. Therefore, before imaging, patients should be instructed to urinate to reduce the degree of tracer uptake in the bladder. Under certain circumstances, urinary catheter irrigation should be considered to lower the background signal.

Table 2. Tracer uptake of different RGD compounds in normal organs 60 min after injection (SUV $V_{\text {mean, }}$ expressed as mean \pm SD).

\begin{tabular}{|c|c|c|c|c|}
\hline \multirow[b]{2}{*}{ Organs } & \multicolumn{4}{|c|}{$S U V_{\text {mean }}$} \\
\hline & $\begin{array}{l}{\left[{ }^{18} \mathrm{~F}\right] \text { Galacto-RGD }} \\
{[33]}\end{array}$ & $\begin{array}{l}\text { [18F]FPPRGD2 } \\
{[38]}\end{array}$ & $\begin{array}{l}\text { [18F]Alfatide } \\
{[26]}\end{array}$ & $\begin{array}{l}{\left[{ }^{68} \mathrm{Ga}\right] P R G D 2} \\
{[36]}\end{array}$ \\
\hline Thyroid & -- & $2.8 \pm 0.7$ & $2.04 \pm 0.35$ & $1.64 \pm 0.42$ \\
\hline Arcus aortae & $1.25 \pm 0.27$ & $1.1 \pm 0.2$ & $1.07 \pm 0.07$ & $1.87 \pm 0.37$ \\
\hline Lungs & $0.43 \pm 0.07$ & $0.5 \pm 0.1$ & $0.26 \pm 0.06$ & $0.64 \pm 0.15$ \\
\hline Liver & $2.69 \pm 0.62$ & $2.2 \pm 0.5$ & $2.74 \pm 0.58$ & $2.21 \pm 0.30$ \\
\hline Spleen & $2.66 \pm 0.59$ & $4.5 \pm 1.0$ & $3.70 \pm 0.60$ & $3.95 \pm 0.81$ \\
\hline Pancreas & -- & $2.5 \pm 0.9$ & -- & $2.34 \pm 0.28$ \\
\hline Kidneys & $5.81 \pm 4.37$ & $7.1 \pm 1.5$ & $5.55 \pm 0.75$ & $7.83 \pm 1.31$ \\
\hline Gastrointestinal & $2.42 \pm 1.46$ & $4.3 \pm 1.1$ & $2.15 \pm 0.28$ & $1.20 \pm 0.50$ \\
\hline Bladder & $76.53 \pm 38.56$ & $64.4 \pm 56.6$ & $69.32 \pm 58.28$ & $13.42 \pm 4.16$ \\
\hline Muscle & $0.47 \pm 0.09$ & $0.5 \pm 0.2$ & $0.49 \pm 0.04$ & $0.52 \pm 0.22$ \\
\hline Tumor/Blood & $3.33 \pm 2.23$ & $3.2 \pm 1.9$ & $2.71 \pm 0.92$ & -- \\
\hline Tumor/Muscle & $7.70 \pm 5.38$ & $5.5 \pm 6.1$ & $5.87 \pm 2.02$ & -- \\
\hline
\end{tabular}




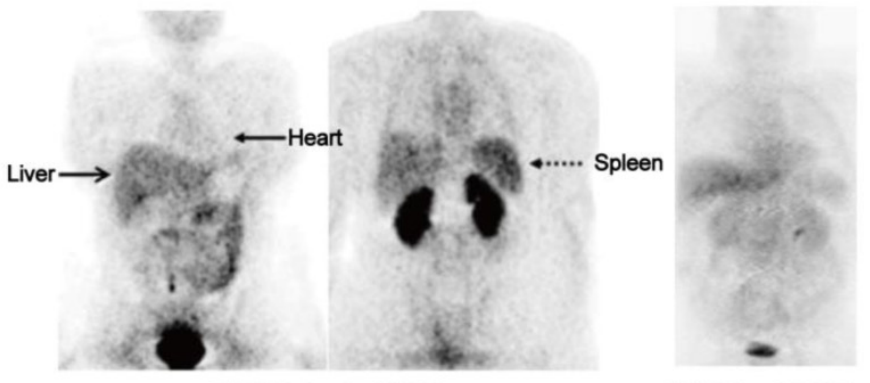

$\left[{ }^{18} \mathrm{~F}\right]$ Galacto-RGD $\left[{ }^{18} \mathrm{~F}\right]$ Fluciclatide

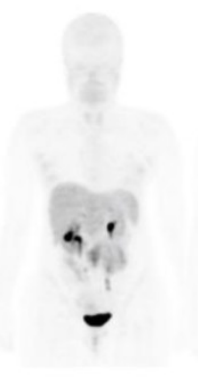

$\left[{ }^{18} \mathrm{~F}\right] \mathrm{RGD}-\mathrm{K} 5$

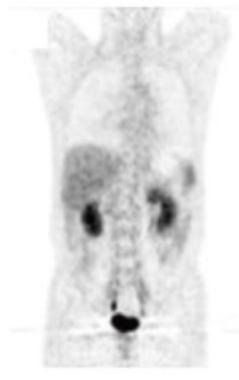

[88G]NOTA-RGD

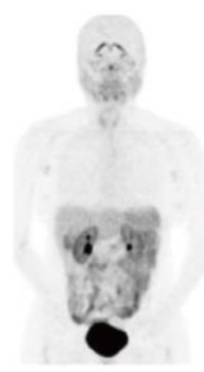

[18 F]FPPRGD2

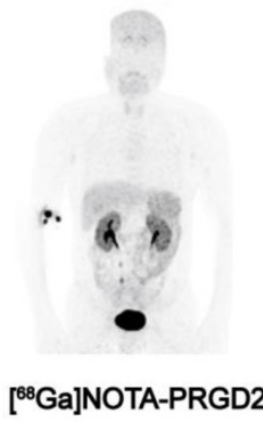

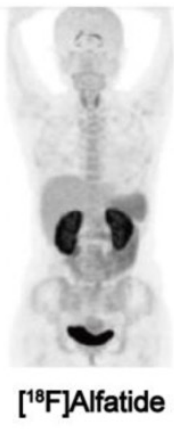

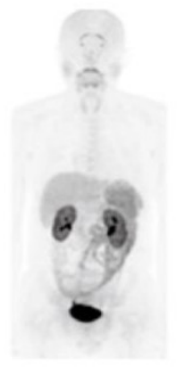

[ ${ }^{18}$ F]Alfatide II

Figure 2. Biodistribution of clinically available RGD-based PET agents $1 \mathrm{~h}$ after intravenous administration in healthy volunteers, except for [18F]-Galacto-RGD PET, which is from a patient with osteomyelitis. All images are coronal views. High tracer retention is notable in urogenital tract, due to predominant renal clearance. Intermediate uptake is found in the liver, spleen, and intestines. Reproduced with the permission from references [46][32][21][31] [34][36][26][35].

The RGD radioligand is retained in the tumor tissue for more than $60 \mathrm{~min}$, whereas the background activity in the blood pool and muscle tissue is low and gradually decreased over time. For example, the blood and plasma clearance curves show that approximately $25 \%$ of $\left[{ }^{18} \mathrm{~F}\right] \mathrm{FPPRGD} 2$ remains in the circulation at $30 \mathrm{~min}$ post-injection (p.i.), and less than $20 \%$ at $60 \mathrm{~min}$ [34]. Therefore, image acquisition at 40-60 min p.i. is recommended as earlier time point scans will have high nonspecific uptake which is likely to affect the image quality and ability to quantify integrin receptor level.

With such biodistribution patterns, RGD PET is well suited for detecting lesions in lungs, mediastinum, head-and-neck area, thorax including the breast, skeletal system and the extremities. Respecting tumors in the liver, spleen, and intestines, the detection efficiency may be unsatisfactory due to the relatively high background activity in these organs. For example, at $1 \mathrm{~h}$ after injection, $\left[{ }^{18} \mathrm{~F}\right] \mathrm{AH} 11185$ shows normal liver uptake with a $S_{U V}$ mean of 3.7-4.6 [37], $\left[{ }^{18} \mathrm{~F}\right]$ Galacto-RGD and $\left[{ }^{18} \mathrm{~F}\right] \mathrm{RGD}-\mathrm{K} 5$ have a liver SU$\mathrm{V}_{\text {mean }}$ of 4 and 2.7 at $1 \mathrm{~h}$ p.i., respectively [21, 33]. PEGylation of the RGD peptide, such as $\left[{ }^{18}\right.$ F]FPPRGD2, decreases lipophilicity and thereby decreases the hepatic uptake. However, the clinical study of [18F]FPPRGD2 still showed a $\mathrm{SUV}_{\text {mean }}$ of 2.2 in the liver [38]. The relatively high physiological liver uptake usually makes it hard to identify liver metastases (SUVs from the liver lesions usually range from
1.4-3.9) [37]. On the other hand, RGD peptide is not able to cross the blood brain barrier (BBB), as tracer uptake in normal brain tissue is even lower than the tracer uptake in background tissue, like muscle [39]. In patients with high-grade glioma (grade III-IV), BBB is partially or completely disrupted, tumor/background ratios are normally remarkable within the area of brain [38, 40,41].

Regarding the stability of these clinically investigated RGD compounds, all of them were confirmed to be stable in vivo after intravenous injection. The radioligands were slowly metabolized to hydrophilic metabolites, with the mean percentage of intact tracer in blood at $120 \mathrm{~min}$ after injection ranging from $75-96 \%[18,42,43]$.

\section{Radiation Dosimetry}

As the patient is exposed to high-energy $\gamma$-rays during the PET scan, knowing the potential risk from radiation exposure is essential in assessing the clinical utility of PET, and this should be quantified and understood so that risk-benefit ratios could be evaluated [44]. According to the literature, the effective dose from [ $\left.{ }^{18} \mathrm{~F}\right] \mathrm{FDG}$ PET/CT, with a diagnostic $\mathrm{CT}$ and 370 $\mathrm{MBq}$ administered FDG dose, is up to $32.18 \mathrm{mSv}$ [45]. However, the effective dose from PET scan is only 6-7 $\mathrm{mSv}(16-18 \mu \mathrm{Sv} / \mathrm{MBq})$, which means the radiation dose to patient from a PET scan is modest and most of the radiation comes from the CT scan.

The effective radiation dose for a 
[18F]Galacto-RGD PET scan was determined to be 17 $\mu \mathrm{Sv} / \mathrm{MBq}$ for male and $20 \mu \mathrm{Sv} / \mathrm{MBq}$ for female [46], which is very similar to an $\left.{ }^{18} \mathrm{~F}\right] \mathrm{FDG}$ PET scan. The mean effective dose of a $370 \mathrm{MBq}$ administered activity of $\left[{ }^{18} \mathrm{~F}\right]$ Fluciclatide was reported to be $9.6 \mathrm{mSv}$ (26 $\mu \mathrm{Sv} / \mathrm{MBq})$ [32], and was $8.3 \mathrm{mSv}(15 \mu \mathrm{Sv} / \mathrm{MBq})$ for a $555 \mathrm{MBq}$ injected dose of [18$\left.{ }^{18} \mathrm{~F}\right] \mathrm{RGD}-\mathrm{K} 5$ [21], both of which are comparable with [18F]FDG PET and $\left[{ }^{18} \mathrm{~F}\right]$ Galacto-RGD. For the dimeric RGD compound, the mean effective dose of [18F]FPPRGD2 was $15 \mathrm{mSv}$ for a $370 \mathrm{MBq}$ injected dose (39.6 $\mu \mathrm{Sv} / \mathrm{MBq})$ [34]. The effecitive dose for [18${ }^{18} \mathrm{~F}$ ]Alfatide II was $17.0 \mu \mathrm{Sv} / \mathrm{MBq}$, determined from 5 healthy volunteers with a bladder void time of $60 \mathrm{~min}$ [35].

For $\left[{ }^{68} \mathrm{Ga}\right]$ NOTA-RGD and $\left[{ }^{68} \mathrm{Ga}\right]$ NOTA-PRGD2, the mean effective doses were reported to be 25.0 $\mu \mathrm{Sv} / \mathrm{MBq}$ and 22.6 $\mu \mathrm{Sv} / \mathrm{MBq}$ [31], which are similar to $\left.{ }^{18} \mathrm{~F}\right]$ Galacto-RGD and $\left.{ }^{18} \mathrm{~F}\right]$ fluciclatide but less than [18F]FPPRGD2. Although ${ }^{68} \mathrm{Ga}$-labeled radiotracers have shorter physical half-life than ${ }^{18} \mathrm{~F}$-labeled radiotracers, this difference is balanced in terms of the radiation dose by the initial kinetic energy of positrons emitted $\left(E_{\max }=1899 \mathrm{keV}\right.$ for ${ }^{68} \mathrm{Ga}$ vs. $633 \mathrm{keV}$ for $\left.{ }^{18} \mathrm{~F}\right)$.

The effective doses of all clinically tested RGD PET tracers range from 10-40 $\mu \mathrm{Sv} / \mathrm{MBq}$ (Table 1). This corresponds to the second risk category defined by 2007 International Commission on Radiological Protection (ICRP), which is greater than $1 \mathrm{mSv}$ but not more than $20 \mathrm{mSv}$ [47]. Overall, ${ }^{18} \mathrm{~F}$-labeled RGD peptides are safe PET tracers with dosimetry profiles comparable to $\left.{ }^{18} \mathrm{~F}\right] \mathrm{FDG}$. Moreover, because RGD-based compounds are mainly cleared out through the urinary tract, the effective dose could be further reduced by reducing the voiding interval. Under certain circumstances, diuretic agents may also be considered to lower the effective dose.

\section{Clinical applications}

\section{Detection of malignant lesions and tumor staging}

One of the applications of RGD PET in the clinic is for tumor detection and staging, as integrin $\alpha_{v} \beta_{3}$ is a well-established biomarker of neoangiogenesis. A wide variety of tumor types were evaluated in clinical studies, e.g. glioblastoma multiforme (GBM), squamous cell carcinoma of the head and neck (SCCHN), non-small cell lung cancer (NSCLC), breast cancer, melanoma, sarcoma, renal cancer, rectal cancer etc., with decent tumor/background contrast (Table 3). For $\left.{ }^{18} \mathrm{~F}\right]$ Galacto-RGD, tracer accumulation in tumor lesions showed great heterogeneity, with mean SUVs ranged between the background level to a maximum of 10 [16] (Figure 3A). Summarized from all the studies reported, the sensitivity of $\left[{ }^{18} \mathrm{~F}\right]$ Galacto-RGD PET for all lesions falls in the range of $59-92 \%$. To be specific, the sensitivity for primary lesions range between $83 \%$ and $100 \%$, however, the sensitivity for metastatic lymph nodes (LNs) was only $33-54 \%$ and was $46-78 \%$ for distant metastases [16, 33, 39, 48-51]. Another ${ }^{18} \mathrm{~F}-$ labled RGD compound $\left[{ }^{18} \mathrm{~F}\right]$ Fluciclatide, like $\left.{ }^{[18} \mathrm{F}\right]$ Galacto-RGD, showed heterogeneous tumor uptake with SUVs from 1.4 to 40 (Figure 3B). The sensitivity for all lesions ranged from $88-94 \%$ and was $71-88 \%$ for distant metastases [37, 52]. These data demonstrated that the monomeric peptide tracer $\left[{ }^{18} \mathrm{~F}\right]$ Galacto-RGD or $\left[{ }^{18} \mathrm{~F}\right]$ Fluciclatide had only moderate sensitivity for metastatic lymph nodes and distant metastases, insufficient for tumor staging.

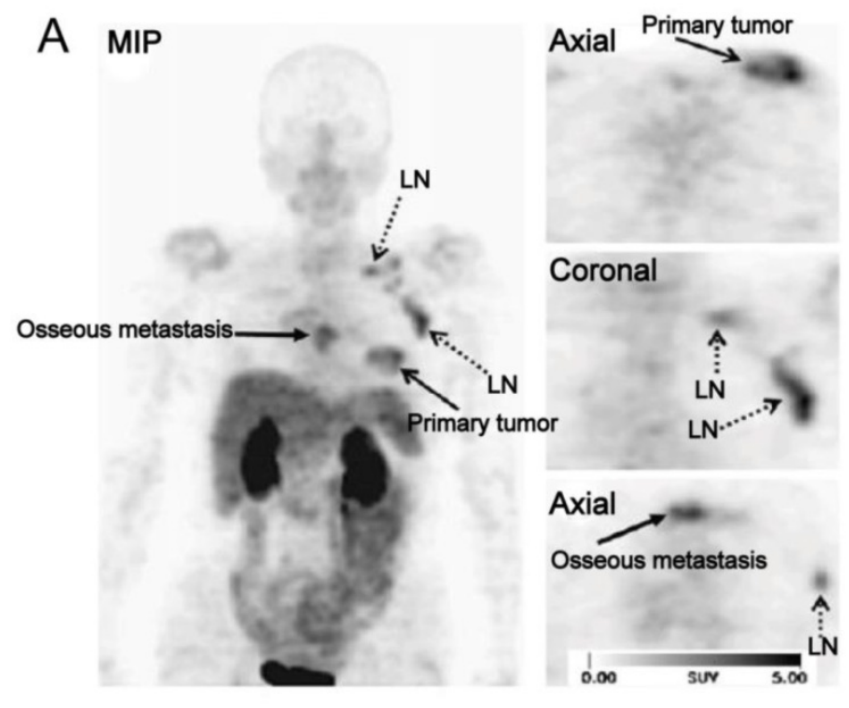

B
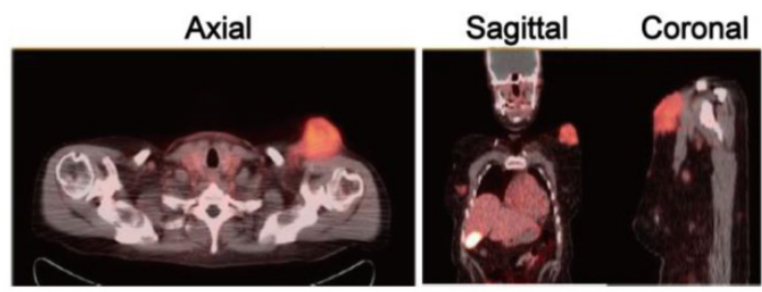

Figure 3. (A) $\left[{ }^{18} \mathrm{~F}\right]$ Galacto-RGD PET images in a patient with invasive ductal breast cancer of left breast, axillary lymph-node metastases on the left side, an osseous metastasis to the sternum, and a pulmonary metastasis on the right side. Maximum-intensity projection of $\left[{ }^{18} \mathrm{~F}\right]$ Galacto-RGD PET and planar images show primary tumor, lymph-node (LN) metastases, and osseous metastasis with good tumor/background contrast. (B) $\left[{ }^{18}\right.$ F]Fluciclatide PET/CT images in a patient with malignant melanoma. Axial, sagittal and coronal images show focal radiotracer uptake within a left supraclavicular mass. Reproduced with permission from references [50][52]. 
Table 3.Tumor diagnostic value of clinically available RGD-based PET tracers

\begin{tabular}{|c|c|c|c|c|c|}
\hline Tracer name & $\begin{array}{l}\text { Patient num- } \\
\text { ber }\end{array}$ & Tumor type & $\begin{array}{l}\text { Detection rate } \\
\text { (Sensitivity) }\end{array}$ & SUVs & Ref \\
\hline [18F]Galacto-RGD & 8 & $\begin{array}{l}5 \text { Melanomas } \\
2 \text { Sarcomas } \\
1 \text { RCC }\end{array}$ & $\begin{array}{l}6 / 7(86 \%), \text { primary lesion } \\
1 / 1(100 \%) \text {, distant metastases } \\
7 / 8(88 \%) \text {, all lesions }\end{array}$ & $1.2-10.0$ & [16] \\
\hline$\left[{ }^{18} \mathrm{~F}\right]$ Galacto-RGD & 19 & $\begin{array}{l}10 \text { Musculoskeletal } \\
4 \text { Melanoma } \\
2 \text { SCCHN } \\
2 \text { GBM } \\
1 \text { Breast cancer }\end{array}$ & $17 / 19(89 \%)$, primary lesion & $1.2-10.0$ & [48] \\
\hline$\left[{ }^{18} \mathrm{~F}\right]$ Galacto-RGD & 11 & 11 SCCHN & $\begin{array}{l}\text { 10/12 (83\%), primary lesion } \\
2 / 6(33 \%), \text { lymph nodes } \\
12 / 18(67 \%) \text {, all lesions }\end{array}$ & $2.2-5.8$ & [49] \\
\hline$\left[{ }^{18} \mathrm{~F}\right]$ Galacto-RGD & 16 & $\begin{array}{l}10 \text { NSCLC } \\
2 \text { RCC } \\
1 \text { SCCHN } \\
1 \text { Rectal cancer } \\
1 \text { Breast cancer }\end{array}$ & $\begin{array}{l}\text { 13/14 (93\%), primary lesion } \\
7 / 13(54 \%), \text { lymph nodes } \\
25 / 32(78 \%), \text { metastases } \\
45 / 59(76 \%) \text {, all lesions }\end{array}$ & $0.3-6.8$ & {$[53]$} \\
\hline$\left[{ }^{18} \mathrm{~F}\right]$ Galacto-RGD & 12 & 12 GBM & $11 / 12(92 \%)$, primary lesion & $0.8-2.8$ & {$[39]$} \\
\hline$\left[{ }^{18} \mathrm{~F}\right]$ Galacto-RGD & 16 & 16 Breast cancer & $\begin{array}{l}12 / 12(100 \%), \text { primary lesion } \\
3 / 8(38 \%), \text { lymph nodes } \\
11 / 24(46 \%), \text { metastases } \\
26 / 44(59 \%) \text {, all lesions }\end{array}$ & $1.4-8.7$ & [50] \\
\hline$\left[{ }^{18} \mathrm{~F}\right]$ Fluciclatide & 7 & 7 Breast cancer & $\begin{array}{l}1 / 1(100 \%), \text { primary lesion } \\
15 / 17(88 \%) \text {, metastases } \\
16 / 17(94 \%) \text {, all lesions }\end{array}$ & $1.4-40.0$ & [37] \\
\hline$\left[{ }^{18} \mathrm{~F}\right]$ Fluciclatide & 17 & $\begin{array}{l}11 \text { RCC } \\
6 \text { Melanoma }\end{array}$ & $\begin{array}{l}10 / 10(100 \%), \text { primary lesion } \\
5 / 7(71 \%), \text { metastases } \\
15 / 17(88 \%) \text {, all lesions }\end{array}$ & $1.8-10.0$ & [52] \\
\hline$\left[{ }^{18} \mathrm{~F}\right] \mathrm{RGD}-\mathrm{K} 5$ & 12 & Breast cancer & $122 / 157(77.7 \%)$, all lesion & & [51] \\
\hline [18F]FPPRGD2 & 8 & Breast cancer & $\begin{array}{l}8 / 8(100 \%), \text { primary lesion } \\
4 / 5(80 \%), \text { lymph nodes } \\
17 / 17(100 \%) \text {, metastases } \\
29 / 30(97 \%) \text {, all lesions }\end{array}$ & $2.4-9.4$ & [65] \\
\hline$\left[{ }^{18} \mathrm{~F}\right] \mathrm{FPPRGD} 2$ & 15 & Recurrent GBM & $17 / 17(100 \%)$, primary lesion & $0.8-5.8$ & {$[41]$} \\
\hline [18F]Alfatide & 9 & NSCLC & 9/9 (100\%), primary lesion & $2.91 \pm 0.73$ & [26] \\
\hline [18F]Alfatide II & 30 & Bone metastases & $\begin{array}{l}100 \% \text {, osteolytic metastases } \\
70 \% \text {, osteoblastic metastases } \\
100 \% \text {, mixed bone metastases } \\
98 \% \text {, bone marrow metastases } \\
92 \% \text {, all metastases }\end{array}$ & $0.95-13.87$ & [66] \\
\hline [18F]Alfatide II & 9 & Brain metastases & $20 / 20(100 \%)$, brain metastases & $1.8-10.0$ & [35] \\
\hline [68Ga]NOTA-PRGD2 & 12 & Glioma & $10 / 12(83.3 \%)$, primary lesion & $0.5-2.31$ & {$[40]$} \\
\hline
\end{tabular}

As a matter of fact, the in vivo biodistribution pattern of RGD affects the detection efficiency of lesions in different regions. The organs with moderate to intense RGD uptake are mostly located in the abdomen and pelvis area, such as the liver, spleen, intestines, kidneys and bladder, making the assessment of metastases rather difficult in these areas. As to the missed LNs or metastases located in the lung, mediastinum, and thorax (area with low background activity), most of reported studies did not obtain tissue samples from these lesions. Therefore, it remains a question mark whether the failure to depict these lesions is a result of technical problems (limited spatial resolution of a clinical PET scanner) or insufficient integrin expression in these lesions.

A direct comparison showed that both $\left[{ }^{18} \mathrm{~F}\right] \mathrm{FDG}$ PET and contrast enhanced CT detected more lesions than $\left.{ }^{18} \mathrm{~F}\right]$ Galacto-RGD PET did [53]. Moreover, it is rather challenging for $\left[{ }^{18} \mathrm{~F}\right]$ Galacto-RGD PET to iden- tify lesions in the liver, due to the relatively intense background activity and therefore lack of contrast between tumor and adjacent normal liver tissue. These pilot data indicate that $\left[{ }^{18} \mathrm{~F}\right] \mathrm{FDG}$ PET may be superior to RGD PET for tumor staging. However, it is worth noting that the tumors with low or intermediate $\left[{ }^{18} \mathrm{~F}\right] \mathrm{FDG}$ uptake, such as prostate cancer or carcinoid tumors, RGD PET may demonstrate better results for lesion detection and tumor staging than [18${ }^{18} \mathrm{~F}$ FDG PET. Moreover, since RGD peptide does not accumulate in normal brains, RGD PET may have higher sensitivity for detecting glioma and higher specificity for determining tumor demarcation, as compared to [18F]FDG PET.

To further improve binding affinity and tumor retention of RGD radioligands, multimeric RGD peptides were introduced [54-59]. Multimerization results in increased tumor uptake, binding affinity and tumor retention, and thus, may enhance the performance of 
integrin imaging [60-62]. However, a higher absolute tumor uptake of multimeric tracers does not necessarily result in improved imaging quality [59]. Indeed, the consequent higher background signals from tetrameric and octameric RGD peptides gave way to the more favorable dimeric scaffold for developing RGD peptide tracers [63].

$\left.{ }^{[18} \mathrm{F}\right]$ FPPRGD2 was the first dimeric RGD peptide tracer applied in the clinic for PET imaging [64]. In a clinical study with 8 breast cancer participants [65], primary and metastatic lesions showed [ $\left.{ }^{18} \mathrm{~F}\right]$ FPPRGD2 uptake with SUVs of 2.4-9.4 (mean, $5.6 \pm 2.8$ ) and 2.5-9.7 (mean, $5.0 \pm 2.3$ ) at $60 \mathrm{~min}$ p.i. (Figure 4A). No significant difference in SUVs was found between $\left[{ }^{18} \mathrm{~F}\right]$ FPPRGD2 and $\left[{ }^{18} \mathrm{~F}\right] \mathrm{FDG}$ PET, for both primary lesions and metastases. Similar results were also reported in a recent study which compared [18F]FPPRGD2 with [18F]FDG PET in 35 patients [38]. The average tumor SUVs from [18F]FPPRGD2 PET is higher than those from $\left[{ }^{18} \mathrm{~F}\right]$ Galacto-RGD and $\left.{ }^{18} \mathrm{~F}\right]$ Fluciclatide PET, which is in accord with the preclinical animal studies [22]. Interestingly, in the case of lobular breast cancer, there was obvious tracer uptake in primary lesion and in sub-centimeter biopsy-proven axillary lymph nodes and thoracic spine metastases, whereas these lesions were not detected by ${ }^{18} \mathrm{~F}-\mathrm{FDG}$ PET. Furthermore, three biopsy-proven inflammatory lymph nodes showed mild ${ }^{18} \mathrm{~F}-\mathrm{FDG}$ uptake but no $\left.{ }^{18} \mathrm{~F}\right]$ FPPRGD2 accumulation. Therefore, the overall sensitivity and specificity of $\left[{ }^{18} \mathrm{~F}\right] \mathrm{FPPRGD} 2$ PET $(95.7 \%$ and $100 \%$, respectively) were higher than those of $\left[{ }^{18} \mathrm{~F}\right]$ FDG PET $(87.0 \%$ and $57.1 \%$, respectively). In a more recent study, [18F]FPPRGD2 PET was performed in 15 patients with recurrent GBM, and compared with $\left[{ }^{18} \mathrm{~F}\right] \mathrm{FDG}$ and brain MR. Surprisingly, $\left[{ }^{18} \mathrm{~F}\right]$ FPPRGD2 PET showed a higher detection rate of recurrent GBM than brain MR $(100.0 \%$ vs. $93.3 \%)$ and $\left[{ }^{18} \mathrm{~F}\right]$ FDG $(100.0 \%$ vs. $86.7 \%)$ [41]. With regard to another dimeric RGD peptide $\left.{ }^{18} \mathrm{~F}\right]$ Alfatide, one clinical study investigated the feasibility of $\left[{ }^{18} \mathrm{~F}\right]$ Alfatide PET for lung cancer detection (Figure 4B). Results showed that [ $\left.{ }^{18} \mathrm{~F}\right]$ Alfatide PET was able to clearly identify all primary lesions (sensitivity is $100 \%$ for primary lesions) with desirable image contrast (mean tumor SUV, 2.9 \pm 1.0 ) [26]. In order to evaluate the diagnostic value of dimeric RGD in metastatic lesions, $\left.{ }^{18} \mathrm{~F}\right]$ Alfatide II PET was recently performed in patients with bone metastases [66] and brain metastases [35], respectively. For bone metastasis from 30 patients, [ $\left.{ }^{18} \mathrm{~F}\right]$ Alfatide II PET/CT has similar detection efficiency as [ $\left.{ }^{18} \mathrm{~F}\right] \mathrm{FDG}$ PET/CT for detecting osteolytic and mixed bone metastases $(100 \%$ vs. $90 \%$ ). However, $\left[{ }^{18} \mathrm{~F}\right]$ Alfatide II is superior to [18F]FDG for osteoblastic lesions (70\% vs. 53\%) (Figure 5). For bone marrow metastatic lesions, the positive rate of [18$\left.{ }^{18} \mathrm{~F}\right]$ Alfatide II PET was also higher than that of [18F]FDG PET (98\% vs. 77\%). In all bone metastatic lesions, no significant difference of tracer uptake was observed between $\left[{ }^{18} \mathrm{~F}\right]$ Alfatide II and $\left.{ }^{18} \mathrm{~F}\right] \mathrm{FDG}(4.27 \pm$ 2.42 vs. $4.18 \pm 2.58, \mathrm{P}>0.05)$. For brain metastases, all 20 brain lesions from 9 patients were visualized by $\left[{ }^{18} \mathrm{~F}\right]$ Alfatide II PET, while only 10 by $\left.{ }^{18}{ }^{18} \mathrm{~F}\right] \mathrm{FDG}$ PET, and 13 by CT. Despite the fact of overall higher tumor uptake of $\left[{ }^{18} \mathrm{~F}\right] \mathrm{FDG}$ over $\left[{ }^{18} \mathrm{~F}\right]$ Alfatide II $(10.0 \pm 5.7 \mathrm{vs}$. $1.8 \pm 1.1)$, $\left[{ }^{18} \mathrm{~F}\right]$ Alfatide II demonstrated much higher tumor/background ratio $(18.9 \pm 14.1)$ than $\left[{ }^{18} \mathrm{~F}\right] \mathrm{FDG}$ $(1.5 \pm 0.5)$, which is consistent with the clinical data from [18F]FPPRGD2 study [41].

Overall, existing clinical studies of $\left[{ }^{18} \mathrm{~F}\right] \mathrm{FPPRGD} 2$ and $\left[{ }^{18} \mathrm{~F}\right]$ Alfatide II showed that both tracers are able to detect integrin-positive tumors with good imaging contrast. These dimeric RGD peptides have comparable imaging properties and pharmacokinetics, and exhibit high sensitivity and specificity for tumor detection and staging. However, besides urogenital system, moderate to prominent tracer uptake in normal liver is also observed from both $\left[{ }^{18} \mathrm{~F}\right]$ FPPRGD2 and $\left[{ }^{18} \mathrm{~F}\right]$ Alfatide PET images. Therefore, it can be an issue when using RGD peptides for detecting tumors within the liver. Based on existing clinical data, the sensitivity of dimeric RGD PET for primary lesions ranges from $83.3-100 \%$ and $70-100 \%$ for metastatic lesions, the specificity of $\left[{ }^{18} \mathrm{~F}\right] \mathrm{FPPRGD} 2$ PET even reached $100 \%$ (only from 8 patients in one study). It is worth noting that $\left[{ }^{18} \mathrm{~F}\right]$ Alfatide and $\left[{ }^{18} \mathrm{~F}\right]$ Alfatide II own a much easier radiosynthetic procedure than $\left[{ }^{18} \mathrm{~F}\right] \mathrm{FPPRGD} 2$, which would lower the bar for large scale clinical trials. Up to now, only a small number of clinical investigations of dimeric RGD peptides were reported, and the sensitivity/specificity between dimers and monomers was never compared in the same patients and will unlikely to be studied. Therefore, additional evaluation with large cohorts are needed to determine if multimeric strategy indeed provides a higher sensitivity and specificity for tumor detection and staging than the monomeric RGD compounds and $\left[{ }^{18} \mathrm{~F}\right] \mathrm{FDG}$.

\section{Noninvasive quantification of tumor integrin $\alpha_{v} \beta_{3}$ expression}

To provide quantitative analysis is one major characteristics of molecular imaging using biomarker specific imaging tracers [14]. High level of inter- and intra-individual variation in RGD uptake from tumor area was observed from clinical studies of RGD PET, indicating heterogeneous integrin $\alpha_{v} \beta_{3}$ expression in different tumor lesions. In patients with various types of tumors, parameters from RGD PET imaging such as SUVs or tumor to blood (T/B) ratios were proved to significantly correlate with the parameters from 
histological examination including intensity of immunohistochemical staining against integrin $\alpha_{v} \beta_{3}$ and microvessel density (MVD) [39, 48-50, 52, 67]. Moreover, immunohistochemistry has confirmed the lack of $a_{v} \beta_{3}$ expression in RGD-negative tumors and nor- mal tissue [48]. These findings highlight such noninvasive imaging techniques hold the potential for appropriate patient selection, especially for those who are going to receive anti- $\alpha_{\mathrm{v}} \beta_{3}$ treatments.

\section{A}

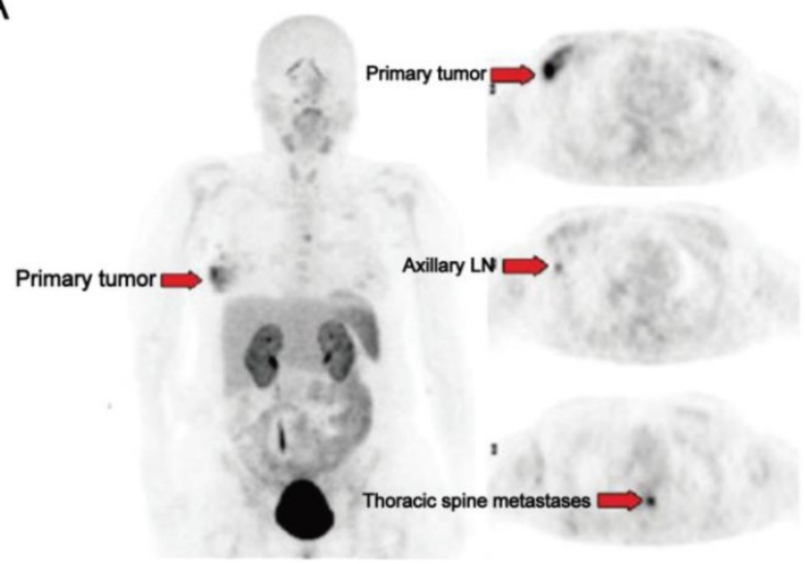

B
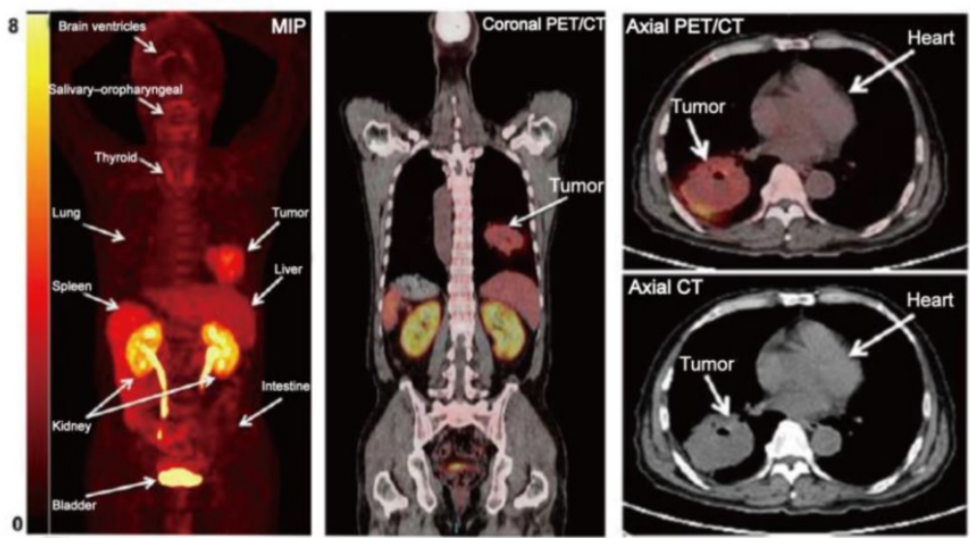

Figure 4. (A) [ ${ }^{18}$ F]FPPRGD2 PET images in a patient with multicentric lobular carcinoma of the right breast. [ ${ }^{8}$ F]FPPRGD2 PET image shows the primary right breast lesion, right axillary lymph node, and thoracic spine metastases (arrows; all proven by biopsy). (B) [18F]Alfatide PET images in a patient with non-small cell lung cancer. Major organs and regions are labeled with arrows. Corresponding PET/CT fusion image at certain coronal slice further shows uptake of tumor and other organs. Reproduced with permission from references [65][26].
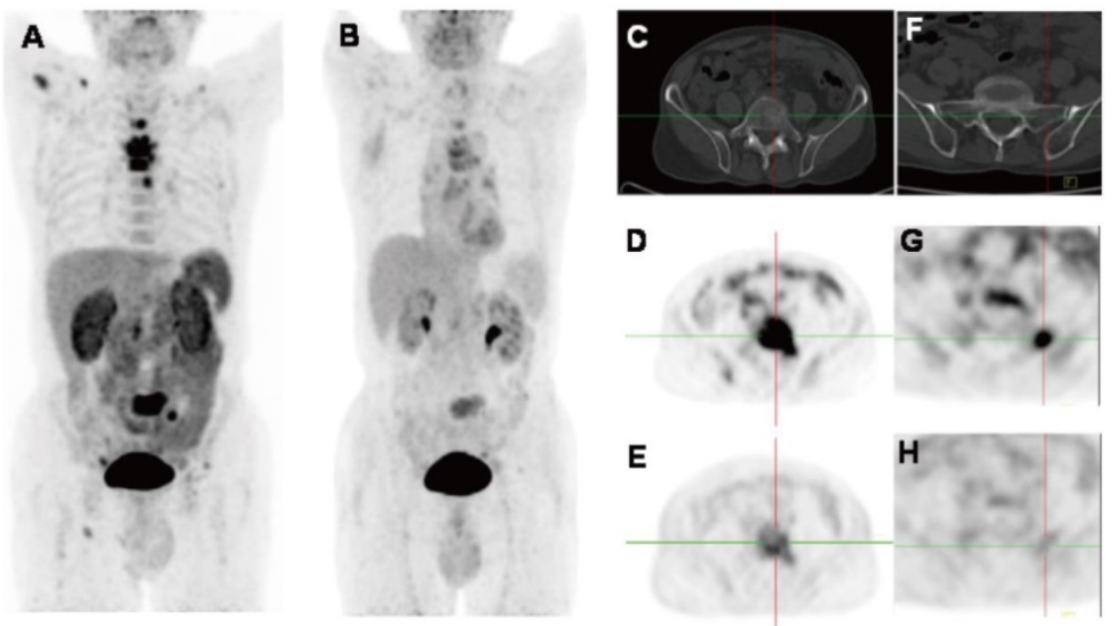

Figure 5. 2D projection images of [ $\left.{ }^{18} \mathrm{~F}\right]$ Alfatide II $(\mathrm{A})$ and $\left[{ }^{18} \mathrm{~F}\right] \mathrm{FDG}$ PET $(\mathrm{B})$ of a patient with metastatic adenocarcinoma of unknown primary site. $\left[{ }^{18} \mathrm{~F}\right] \mathrm{Alfatide}$ II PET demonstrated intense local accumulation of radioactivity in the bone metastatic lesions located in thoracic vertebras, sacrum and right scapula, and right clavicle with good background contrast, whereas [18F]FDG PET only showed moderate uptake in some thoracic vertebras and sacral lesions. The transaxial CT (C), [18F]Alfatide II PET (D), and [ ${ }^{18}$ F]FDG PET(E) were presented to focus on the lesions at sacrum. There is also bone metastasis with abnormal [18F]Alfatide II uptake (G) but not visible by transaxial CT (F) or [ ${ }^{18}$ F]FDG PET(H). Reproduced with permission from reference [66]. 
However, $a_{v} \beta_{3}$ is not only expressed on neovasculature, but also on the surface of some tumor cells as well, particularly in melanoma, glioma, and renal cell carcinoma [68]. Therefore, it is important to keep in mind that RGD PET does not necessarily reflect angiogenesis in all tumor types because tumoral expression of integrin $\alpha_{v} \beta_{3}$ was not excluded. For example, tumor uptake of $\left[{ }^{18} \mathrm{~F}\right]$ FPRGD2 were compared with integrin $\alpha_{v} \beta_{3}$ expression and histological markers of angiogenesis in 27 renal cell carcinoma (RCC) patients. In the group of clear cell RCC (ccRCC), the $\left[{ }^{18} \mathrm{~F}\right]$ FPRGD2 PET signal correlated with integrin $\alpha_{v} \beta_{3}$ expression by tumor cells and IHC results confirmed high expression of $\alpha_{v} \beta_{3}$ on ccRCC cells, whereas in the papillary RCC ( $\mathrm{pRCC}$ ) group, the signal correlated with integrin $\alpha_{v} \beta_{3}$ level on tumor vessels [67]. These results demonstrated that RGD uptake reflects the expression of integrin $\alpha_{v} \beta_{3}$ in renal tumors but represents angiogenesis only when tumor cells do not express integrin $\alpha_{\mathrm{v}} \beta_{3}$.

Up to now, several different tumor types have been systematically examined regarding their $a_{v} \beta_{3}$ expression patterns as shown by RGD PET. In patients with SCCHN, immunohistochemistry showed predominant $a_{v} \beta_{3}$ expression on tumor vasculature but not on tumor cells, thus in SCCHN, RGD PET may be regarded as a surrogate marker of angiogenesis [49]. However, in malignant melanoma and ccRCC, it is not appropriate to use RGD PET to evaluate angiogenesis, because $\alpha_{v} \beta_{3}$ is also highly expressive on the surface of these tumor cells [52]. Consequently, the interpretation of RGD PET imaging strongly depends on the tumor type analyzed, which still needs further investigation.

Imaging $\alpha_{v} \beta_{3}$ expression with RGD PET has been advocated for lesion detection but is not consistent with $\left[{ }^{18} \mathrm{~F}\right]$ FDG PET. In one study which compared $\left[{ }^{18} \mathrm{~F}\right]$ Galacto-RGD with $\left[{ }^{18} \mathrm{~F}\right]$ FDG PET, no correlation between FDG and RGD PET parameter in 18 patients with NSCLC and various other tumors was found $(\mathrm{r}=$ 0.157) [53]. Similar results were reported in a recent study which compared ${ }^{68} \mathrm{Ga}-\mathrm{RGD}$ and $\left[{ }^{18} \mathrm{~F}\right] \mathrm{FDG}$ PET/CT in different types of breast cancers [69]. This finding may be explained by the different accumulation mechanisms of the two compounds since FDG reflects the distribution of glucose uptake and phosphorylation by tumor cells, but RGD binds to integrin $\alpha_{v} \beta_{3}$ expressed on the surface of tumor cells and activated endothelial cells. It is also interesting to note that bone metastases showed a tendency of high RGD uptake [66], which corroborates with the observation that integrin $\alpha_{v} \beta_{3}$ is an indicator for bone metastases [70]. Therefore, [18F]FDG and [18F]RGD PET provide complementary molecular information about tumors.

\section{Applications beyond oncology}

Ischemic vascular diseases, including myocardial infarction (MI) and stroke, have been the leading causes of death and disability worldwide. Angiogenesis is considered an integral part of the repair process after ischemic injury and has been a major focus of cardiovascular and neurovascular research [71]. Integrin $\alpha_{v} \beta_{3}$ may be an important theranostic target associated with post-MI and post-stroke repair processes after ischemic injury [72]. In one investigation, a patient with myocardial infarction underwent [18F]Galacto-RGD PET/CT scan two weeks after percutaneous coronary intervention [73]. Focal tracer retention was found in the infarcted area, which was defined by the extent of delayed enhancement from MRI and severely reduced myocardial blood flow from ${ }^{13} \mathrm{~N}$-ammonia PET/CT. This signal may suggest that myocardial healing was taking place within the infarcted area. More recently, [ ${ }^{68} \mathrm{Ga}$ ]NOTA-PRGD2 $\mathrm{PET} / \mathrm{CT}$ was employed to evaluate integrin $\mathrm{a}_{\mathrm{v}} \beta_{3}$-related repair in 23 post-MI and 16 post-stroke patients [74]. Patchy [ ${ }^{68 \mathrm{Ga}}$ ]NOTA-PRGD2 uptake was found to be located at or immediately around the ischemic regions in 20/23 MI patients and punctate multifocal uptake occurred in 8/16 stroke patients. Moreover, $\left.{ }^{68} \mathrm{Ga}\right]$ NOTA-PRGD2 uptake related with the disease phase and severity, suggesting that RGD PET can provide valuable semi-quantitative information about post-MI and post-stroke repair. Thus, noninvasive RGD PET appears to be promising for assessing therapies aiming to stimulate angiogenesis in ischemic vascular diseases.

Moyamoya disease (MMD), a progressive occlusive disease of the distal internal carotid artery, is one of the most important causes of cerebral infarct in children [75]. The disease is the most common pediatric cerebral vascular disease that requires surgical intervention as it does not respond to any current medical treatment [76]. Indirect revascularization is the most widely used treatment for pediatric MMD [77]. Because angiogenesis and collateral vessel formation is the key mechanism in indirect revascularization surgery for MMD, and integrin $\alpha_{v} \beta_{3}$ is overexpressed on endothelial cells of newly formed vessels, the assessment of angiogenic activity by RGD PET might be beneficial for investigating the revascularization mechanism and evaluating the efficacy of treatment. ${ }^{88} \mathrm{Ga}$-RGD PET was thus performed in pediatric MMD patients undergoing indirect revascularization surgery, to evaluate angiogenic activity and its correlation with treatment efficacy [78]. [ $\left.{ }^{68} \mathrm{Ga}\right]$ RGD PET exhibited increased tracer uptake mainly around the bony flap including adjacent tissue such as galea, suggesting angiogenic activation in the acute post-infarct area. The author also demonstrated that 
angiogenic activity gradually decreased in a time-dependent manner and was estimated to normalize at approximately 6 months after surgery. Thus, the assessment of angiogenic activity using RGD PET is expected to be an effective tool for evaluating the efficacy of revascularization therapy in MMD patients.

Atherosclerosis is the major reason for most clinical cardiovascular events, and inflammation and intraplaque angiogenesis are important features of atherosclerotic plaque progression and vulnerability [79-81]. In atherosclerotic lesions, both macrophages and activated endothelial cells highly express integrin $\alpha_{v} \beta_{3}$ [82]. Therefore, imaging integrin $\alpha_{v} \beta_{3}$ expression may be helpful to predict future risk of plaque rupture and allow evaluating anti-atherosclerotic therapy response. In a study involving patients with high grade carotid stenosis, Beer et al. [83] have demonstrated the feasibility of [18F]Galacto-RGD PET/CT to visualize atherosclerotic lesions and evaluate integrin $\mathrm{a}_{\mathrm{v}} \beta_{3}$ expression in plaques. Focal [18F]Galacto-RGD uptake can be visualized in atherosclerotic lesions, and the uptake significantly correlated with intraplaque $\alpha_{v} \beta_{3}$ expression, suggesting that visualization of integrin $\alpha_{v} \beta_{3}$ expression in human plaques is generally possible with PET imaging by using appropriate RGD tracers.

Rheumatoid arthritis (RA) is one of the most common rheumatic disorders. RGD peptide tracers hold the potential for diagnosing and therapy response monitoring in RA because synovial angiogenesis and pannus formation are major histopathological findings in patients with RA. One clinical study used [ $\left.{ }^{68} \mathrm{Ga}\right]$ PRGD2 PET to evaluate synovial angiogenesis and monitor response to treatment in patients with active RA [84]. High levels of $\left[{ }^{68} \mathrm{Ga}\right]$ PRGD2 accumulation were found in the involved joints and tendon sheaths and diffuse distribution in the lining of the synovium. Additionally, in patients with intense $\left[{ }^{18} \mathrm{~F}\right] \mathrm{FDG}$ uptake in muscles caused by arthritic pain, $\left.{ }^{68} \mathrm{Ga}\right]$ PRGD2 PET/CT was found to be better able to evaluate disease severity than $\left[{ }^{18} \mathrm{~F}\right] \mathrm{FDG}$ PET/CT. Moreover, the change of $\left[{ }^{68} \mathrm{Ga}\right] \mathrm{PRGD} 2 \mathrm{ac}-$ cumulation was found to be in response to therapeutic intervention, and the changes in [ $\left.{ }^{68} \mathrm{Ga}\right]$ PRGD2 uptake significantly correlated with the changes in clinical disease activity index. From this study, RGD PET/CT appears to be an effective tool for identifying and assessing inflammatory synovial angiogenesis in RA patients.

\section{Other perspective clinical applications}

\section{Patient risk stratification and patient selection for antiangiogenic therapy}

Since integrin $\alpha_{v} \beta_{3}$ is an essential hallmark of tumor growth, invasion and metastasis, imaging integrin $\alpha_{v} \beta_{3}$ expression with PET is potentially interesting for patient risk stratification and patient selection for antiangiogenic therapy. In preclinical studies, expression of integrin $\alpha_{v} \beta_{3}$ has been reported to be associated with tumor aggressiveness and metastatic potential in malignant tumors [4]. For example, integrin $\alpha_{v} \beta_{3}$ plays an essential role in the progression of malignant melanoma, during the transition of cells from radial growth phase to the vertical growth phase [85]. [ $\left.{ }^{18} \mathrm{~F}\right]$ Galacto-RGD PET observed high variations of tumor uptake in melanoma patients [33]. For sarcoma and glioma, RGD uptake was positively correlated with the grade of tumor differentiation [40,48]. Preclinical studies have also shown that expression level of integrin $\alpha_{v} \beta_{3}$ is associated with tumor aggressiveness and metastatic potential of breast cancer [86], and integrin targeted therapy with Cilengitide showed promising results in breast cancer tumor-bearing mice [87]. Therefore, RGD PET may be effective for patient risk stratification. In addition, integrin $\alpha_{v} \beta_{3}$ imaging with RGD peptide tracers might also be useful in determining patient integrin status before starting therapies against the same target (such as Cilengitide). The current controversial findings and limited success especially in multicenter clinical trials with Cilengitide as monotherapy or as an adjuvant to the standard of care might suggest the importance of integrin imaging prior to patient recruitment. It is hopeful that companion integrin imaging and anti-integrin therapy, or integrin targeted theranostics, will likely have better outcomes. Patient stratification by integrin imaging will only enroll patients with medium to high integrin expression. Those patients with low levels of $a_{v} \beta_{3}$ will be switched to alternative treatment regimens in the first place, avoiding ineffective treatment.

\section{Therapy response monitoring}

Although a good number of angiogenesis inhibitors are now being used in the clinic, it is also important to note that not all patients benefit from therapy with a specific antiangiogenic drug, and some tumors may become resistant to such therapy. As integrin $\alpha_{v} \beta_{3}$ is a key player in angiogenesis, it therefore can act as a predictive biomarker to select patients who will most likely benefit from a specific angiogenesis inhibitor, to evaluate treatment response, and to detect emerging resistance. Therefore, imaging integrin $\alpha_{v} \beta_{3}$ expression might be a useful method for 
early predicting antiangiogenic therapy response. This is particularly important as antiangiogenic therapy usually leads to a delay of tumor growth, rather than tumor shrinkage. As such, traditional imaging methods that only monitor morphologic changes will not be appropriate.

Currently, there are some preclinical studies on the use of RGD-based PET tracers for antiangiogenic therapy response monitoring. Unlike previous researches [88, 89], these studies mostly focus on the tumor models in which integrin $\alpha_{v} \beta_{3}$ is mainly expressed on tumor vasculature, thus, the signal from RGD PET imaging only reflects $\alpha_{v} \beta_{3}$ expression on activated endothelial cells of the tumor vasculature. However, the results are still controversial. Some studies indicate that RGD PET is capable of measuring the changes of neovascular density and integrin expression during antiangiogenic therapy [90, 91]. However, other studies concluded that the tumor uptake of RGD peptide does not necessarily reflect changes of $\alpha_{v} \beta_{3}$ expression by intratumoral blood vessels early during the course of antiangiogenic therapy [92]. Thus, the efficacy of RGD PET imaging for tumor therapy monitoring relies heavily on the therapy protocol and tumor type analyzed.

Moreover, the findings regarding monitoring antiangiogenic therapies with RGD PET are confined to experimental animals. A well-defined clinical trial using $\alpha_{v} \beta_{3}$ imaging as a surrogate marker to assess response to antiangiogenic therapies is going to be the most important next step. This is difficult to carry out as many antiangiogenic drugs are now combined with chemotherapy, it is therefore not clear whether the change observed in the PET signals is due to the decreased angiogenesis or other factors like apoptosis or necrosis induced by chemotherapy. Hopefully, through imaging $a_{v} \beta_{3}$ expression, we'll get a new tool at hand for guiding and tailoring antiangiogenic treatments to achieve individualized medicine.

\section{Limitations of RGD compounds}

As most RGD peptides have predominant renal clearance, this will impair detection of lesions in the urogenital tract. As such, tumors such as transitional cell carcinoma of bladder and urethra, localized prostate cancer and renal cancer are unlikely to be fully visualized by RGD PET. To a less extent this also applies to organs located in the abdominal area, such as spleen, liver and intestines. There is usually moderate to intense metabolic uptake in these organs (SUVs ranging from 2.5 to 4.0 at 1 h p.i.) $[26,33,37$, 65].

Furthermore, as we have mentioned before, RGD PET does not necessarily allow specific visualization of angiogenesis in all tumor types because tumoral expression of integrin $\alpha_{v} \beta_{3}$ was not excluded. Thus, the interpretation of RGD PET is complex, and the potential of imaging integrin $\alpha_{v} \beta_{3}$ expression as a genuine biomarker of angiogenesis relies on the tumor type analyzed.

Another problem is the specificity of the signal obtained by RGD PET. This is because integrin $\alpha_{v} \beta_{3}$ can also be highly expressed on various of benign cells, such as smooth muscle cells, macrophages and osteoclasts. This has been confirmed by a number of clinical studies, e.g., myocardial infarction [93, 94], atherosclerosis [83], and cerebral infarct [95]. RGD-based compounds can also accumulate in some inflammatory lesions, such as cutaneous delayed-type hypersensitivity reaction [96], villonodular synovitis [16], hemangioma [53, 97] and oncocytoma [67]. This is because inflammatory lesions also involve neovasculature with activated endothelial cells which express integrin $\alpha_{v} \beta_{3}$. Therefore, like [18F]FDG PET, RGD PET may not be able to differentiate inflammatory disease from malignant tumors effectively.

As for image quantification of RGD PET, the parameters from static PET scans, like SUV, \%ID/g, are being widely used. However, besides the tracer binding affinity, the ability to convert tissue uptake into target concentration is unavoidably affected by other factors such as heterogeneity of blood supply, interstitial fluid pressure and vascular permeability. According to preclinical researches from Chen's group [98, 99], dynamic RGD PET followed by the three compartment kinetic modeling can be used to discern specific integrin binding in tissue as it delineates specific uptake from the non-specific accumulation of RGD tracers in the tumor region. Moreover, parametric imaging from dynamic PET with RGD tracer demonstrates advantages in distinguishing effective from ineffective therapy early during vascular-disrupting [100] or chemotherapeutic [101] treatment. Therefore, quantitative analysis according to dynamic PET provides more sensitive evaluation than static PET. In one pilot clinical study with 18 lesions from 7 breast cancer patients, the kinetics of $\left[{ }^{18} \mathrm{~F}\right]$ fluciclatide has been established by using a two-tissue reversible binding model, the $\mathrm{k}_{3} / \mathrm{k}_{4}$ ratio was found to be a reasonable measure of specific binding, which suggests that this index could be used for estimating $\alpha_{v} \beta_{3}$ expression in cancer lesions [102]. More recently, multi-bed-position dynamic imaging of $\left.{ }^{68} \mathrm{Ga}\right]$ NOTA-PRGD2 was successfully performed in lung cancer patients [97]. Compared with static images, parametric maps showed substantial increase of tumor-background ratio and pixel-wise quantification of integrin expression in primary and metastatic lesions throughout the body. 

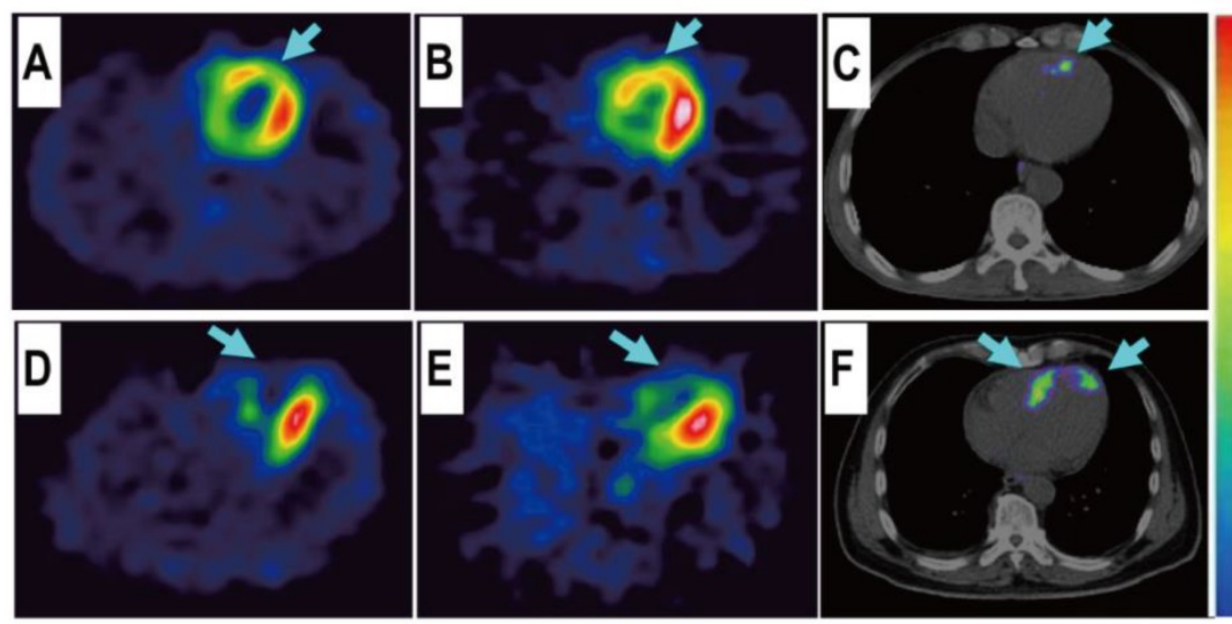

$99 \mathrm{mTC}-\mathrm{MIBI}$

${ }^{18}$ F-FDG

${ }^{68} \mathrm{Ga}-\mathrm{PRGD} 2$

Figure 6. Comparison of a patient with slight myocardial infarction (MI) and a patient with severe MI. Upper row: In a 58 -year-old man at day 5 after the event, a small apical region with decreased [ ${ }^{99 \mathrm{mTC}}$ ]MIBI perfusion (A, arrow) and [18F]FDG metabolism (B, arrow) showed mild [ ${ }^{68 G a}$ ]NOTA-PRGD2 accumulation (C, arrow). Lower row: In a 45-year-old woman on the 7th day after the event, an apical defect on [99mTc]MIBI perfusion images (D, arrow) and [18F]FDG metabolism images (E, arrow) corresponded with moderate [ $\left.{ }^{68} \mathrm{Ga}\right]$ NOTA-PRGD2 uptake (F, arrows). Reproduced with permission from reference [74].

\section{Conclusion}

Great efforts have been made to develop radiolabeled RGD peptides for non-invasive determination of $\mathrm{a}_{\mathrm{v}} \beta_{3}$ expression as well as monitoring tumor repsone to therapeutics involving angiogenesis. Some of them like $\left[{ }^{18} \mathrm{~F}\right]$ Galacto-RGD, $\left[{ }^{18} \mathrm{~F}\right]$ Fluciclatide, $\left[{ }^{18} \mathrm{~F}\right] \mathrm{RGD}-\mathrm{K5}, \quad\left[{ }^{68} \mathrm{Ga}\right]$ NOTA-RGD, $\quad\left[{ }^{68} \mathrm{Ga}\right]$ NOTAPRGD2, [ $\left.{ }^{18} \mathrm{~F}\right] \mathrm{FPPRGD} 2$, and $\left[{ }^{18} \mathrm{~F}\right]$ Alfatide II are currently under clinical investigations for the identification of malignant lesions and quantitative assessment of integrin $a_{v} \beta_{3}$ expression. Among them, $\left[{ }^{18} \mathrm{~F}\right]$ Alfatide II and $\left[{ }^{68} \mathrm{Ga}\right]$ NOTA-PRGD2 substantiated their advantages including easy preparation, fast labeling and superior in vivo pharmacokinetics than most of the existing monomeric RGD peptides. These tracers demonstrated the potential value of non-invasive techniques for patient risk stratification, patient selection for $\alpha_{v} \beta_{3}$-targeting therapies and monitoring of patients receiving such therapies. Therefore, to define the ultimate role of imaging $\alpha_{v} \beta_{3}$ expression in the clinic, large scale clinical trials using radiolabeled RGD tracers for therapy response assessment or patient prognosis evaluation are warranted.

\section{Acknowledgment}

The authors gratefully acknowledge the National Natural Science Foundation of China (81471684 and 81371596) and the Intramural Research Program, National Institute of Biomedical Imaging and Bioengineering, National Institutes of Health. Haojun Chen was partially funded by the China Scholarship Council (CSC).

\section{Competing Interests}

The authors have declared that no competing interest exists.

\section{References}

1. Carmeliet P. Angiogenesis in health and disease. Nat Med. 2003; 9: 653-60.

2. Folkman J. Angiogenesis in cancer, vascular, rheumatoid and other disease. Nat Med. 1995; 1: 27-31.

3. Avraamides CJ, Garmy-Susini B, Varner JA. Integrins in angiogenesis and lymphangiogenesis. Nat Rev Cancer. 2008; 8: 604-17.

4. Niu G, Chen $X$. Why integrin as a primary target for imaging and therapy. Theranostics. 2011; 1: 30-47.

5. Chen X. Integrin targeted imaging and therapy. Theranostics. 2011; 1: 28.

6. Takada Y, Ye X, Simon S. The integrins. Genome Biol. 2007; 8: 215.

7. Zitzmann S, Ehemann V, Schwab M. Arginine-glycine-aspartic acid (RGD)-peptide binds to both tumor and tumor-endothelial cells in vivo. Cancer Res. 2002; 62: 5139-43.

8. Cai W, Niu G, Chen X. Imaging of integrins as biomarkers for tumor angiogenesis. Curr Pharm Des. 2008; 14: 2943-73.

9. Wu H, Chen $\mathrm{H}$, Sun $\mathrm{Y}$, Wan $\mathrm{Y}$, Wang F, Jia B, et al. Imaging integrin av $\beta 3$ positive glioma with a novel RGD dimer probe and the impact of antiangiogenic agent (Endostar) on its tumor uptake. Cancer Lett. 2013; 335: $75-80$

10. Wu H, Chen H, Pan D, Ma Y, Liang S, Wan $Y$, et al. Imaging integrin alphavbeta 3 and NRP-1 positive gliomas with a novel fluorine-18 labeled RGD-ATWLPPR heterodimeric peptide probe. Molecular Imaging Biol. 2014; 16: 781-92.

11. Iagaru A, Gambhir SS. Imaging tumor angiogenesis: the road to clinical utility. AJR Am J Roentgenol. 2013; 201: W183-91.

12. Haubner R, Beer AJ, Wang H, Chen X. Positron emission tomography tracers for imaging angiogenesis. Eur J Nucl Med Mol Imaging. 2010; 37 Suppl 1: S86-103.

13. Ye $Y$, Chen $X$. Integrin targeting for tumor optical imaging. Theranostics. 2011; 1: 102.

14. Massoud TF, Gambhir SS. Molecular imaging in living subjects: seeing fundamental biological processes in a new light Genes Dev. 2003 $17 \cdot 545-80$.

15. Hooker JM. Modular strategies for PET imaging agents. Curr Opin Chem Biol. 2010; 14: 105-11.

16. Haubner R, Weber WA, Beer AJ, Vabuliene E, Reim D, Sarbia M, et al. Noninvasive visualization of the activated av $\beta 3$ integrin in cancer patients by positron emission tomography and $\left.{ }^{18} \mathrm{~F}\right]$ Galacto-RGD. PLoS Med. 2005; 2: e70.

17. Haubner R, Kuhnast B, Mang C, Weber WA, Kessler H, Wester HJ, et al. [18F]Galacto-RGD: synthesis, radiolabeling, metabolic stability, and radiation dose estimates. Bioconjug Chem. 2004; 15: 61-9.

18. Beer AJ, Schwaiger M. PET imaging of av $\beta 3$ expression in cancer patients. Methods Mol Biol. 2011; 680: 183-200.

19. Glaser M, Morrison M, Solbakken M, Arukwe J, Karlsen H, Wiggen U, et al. Radiosynthesis and biodistribution of cyclic RGD peptides conjugated with novel $\left[{ }^{18} \mathrm{~F}\right]$ fluorinated aldehyde-containing prosthetic groups. Bioconjug Chem. 2008; 19: 951-7. 
20. Kolb H, Chen K, Walsh J, Chen G, Gangadharmath U, Kasi D, et al. Synthesis and imaging of an ${ }^{18} \mathrm{~F}$-labeled RGD peptide for detecting av $\beta 3$ integrin expression in vivo J Label Compd Radiopharm. 2009; 52: S67-S.

21. Doss M, Kolb HC, Zhang JJ, Belanger MJ, Stubbs JB, Stabin MG, et al. Biodistribution and radiation dosimetry of the integrin marker ${ }^{18} \mathrm{~F}-\mathrm{RGD}-\mathrm{K} 5$ determined from whole-body PET/CT in monkeys and humans. J Nucl Med. 2012; 53: 787-95.

22. Liu S, Liu Z, Chen K, Yan Y, Watzlowik P, Wester HJ, et al. ${ }^{18}$ F-labeled galacto and PEGylated RGD dimers for PET imaging of av $\beta 3$ integrin expression. Mol Imaging Biol. 2010; 12: 530-8.

23. McBride WJ, Sharkey RM, Karacay H, D'Souza CA, Rossi EA, Laverman P, et al. A novel method of 18F radiolabeling for PET. J Nucl Med. 2009; 50: 991-8.

24. McBride WJ, D'Souza CA, Sharkey RM, Karacay H, Rossi EA, Chang CH, et al. Improved ${ }^{18} \mathrm{~F}$ labeling of peptides with a fluoride-aluminum-chelate complex. Bioconjug Chem. 2010; 21: 1331-40.

25. Lang L, Li W, Guo N, Ma Y, Zhu L, Kiesewetter DO, et al. Comparison study of [ $\left.{ }^{18} \mathrm{~F}\right]$ FAl-NOTA-PRGD2, $\left.{ }^{18} \mathrm{~F}\right]$ FPPRGD2, and [68 Ga]Ga-NOTA-PRGD2 for PET imaging of U87MG tumors in mice. Bioconjug Chem. 2011; 22: 2415-22.

26. Wan W, Guo N, Pan D, Yu C, Weng Y, Luo S, et al. First experience of ${ }^{18} \mathrm{~F}$-Alfatide in lung cancer patients using a new lyophilized kit for rapid radiofluorination. J Nucl Med. 2013; 54: 691-8.

27. Lang L, Ma Y, Kiesewetter DO, Chen X. Stability analysis of glutamic acid linked peptides coupled to NOTA through different chemical linkages. Mol Pharm. 2014; 11: 3867-74.

28. Guo J, Lang L, Hu S, Guo N, Zhu L, Sun Z, et al. Comparison of three dimeric 18F-AlF-NOTA-RGD tracers. Mol Imaging Biol. 2014; 16: 274-83.

29. Wu C, Yue X, Lang L, Kiesewetter DO, Li F, Zhu Z, et al. Longitudinal PET imaging of muscular inflammation using ${ }^{18} \mathrm{~F}-\mathrm{DPA}-714$ and ${ }^{18} \mathrm{~F}-\mathrm{Alfatide}$ II and differentiation with tumors. Theranostics. 2014; 4: 546-55.

30. Jeong JM, Hong MK, Chang YS, Lee YS, Kim YJ, Cheon GJ, et al. Preparation of promising angiogenesis PET imaging agent: ${ }^{68} \mathrm{Ga}$-labeled c(RGDyK)-isothiocyanatobenzyl-1,4,7-triazacyclononane-1,4,7-triacetic acid and feasibility studies in mice. J Nucl Med. 2008; 49: 830-6.

31. Kim JH, Lee JS, Kang KW, Lee HY, Han SW, Kim TY, et al. Whole-body distribution and radiation dosimetry of ${ }^{68} \mathrm{Ga}-\mathrm{NOTA}-\mathrm{RGD}$, a positron emission tomography agent for angiogenesis imaging. Cancer Biother Radiopharm. 2012; 27: 65-71.

32. McParland BJ, Miller MP, Spinks TJ, Kenny LM, Osman S, Khela MK, et al. The biodistribution and radiation dosimetry of the Arg-Gly-Asp peptide ${ }^{18} \mathrm{~F}-\mathrm{AH} 111585$ in healthy volunteers. J Nucl Med. 2008; 49: 1664-7.

33. Beer AJ, Haubner R, Goebel M, Luderschmidt S, Spilker ME, Wester HJ, et al. Biodistribution and pharmacokinetics of the av $\beta 3$-selective tracer ${ }^{18} \mathrm{~F}$-galacto-RGD in cancer patients. J Nucl Med. 2005; 46: 1333-41.

34. Mittra ES, Goris ML, Iagaru AH, Kardan A, Burton L, Berganos R, et al. Pilot pharmacokinetic and dosimetric studies of 18F-FPPRGD2: a PET radiopharmaceutical agent for imaging av $\beta 3$ integrin levels. Radiology. 2011; 260: 182-91.

35. Yu C, Pan D, Mi B, Xu Y, Lang L, Niu G, et al, 18F-Alfatide II PET/CT in healthy human volunteers and patients with brain metastases. Eur J Nucl med Mol Imaging. 2015 in press. DOI 10.1007/s00259-015-3118-2

36. Zheng K, Liang N, Zhang J, Lang L, Zhang W, Li S, et al. ${ }^{68}$ Ga-NOTA-PRGD2 PET/CT for integrin imaging in patients with lung cancer. J Nucl Med, 2015 Oct 1. pii: jnumed.115.160648. [Epub ahead of print]

37. Kenny LM, Coombes RC, Oulie I, Contractor KB, Miller M, Spinks TJ, et al. Phase I trial of the positron-emitting Arg-Gly-Asp (RGD) peptide radioligand ${ }^{18} \mathrm{~F}-\mathrm{AH} 111585$ in breast cancer patients. J Nucl Med. 2008; 49: 879-86.

38. Minamimoto R, Jamali M, Barkhodari A, Mosci C, Mittra E, Shen B, et al. Biodistribution of the 18F-FPPRGD2 PET radiopharmaceutical in cancer patients: an atlas of SUV measurements. Eur J Nucl Med Mol Imaging. 2015, in press. DOI 10.1007/s00259-015-3096-4

39. Schnell O, Krebs B, Carlsen J, Miederer I, Goetz C, Goldbrunner RH, et al. Imaging of integrin av $\beta 3$ expression in patients with malignant glioma by [18 $\mathrm{F}]$ Galacto-RGD positron emission tomography. Neuro Oncol. 2009; 11: 861-70.

40. Li D, Zhao X, Zhang L, Li F, Ji N, Gao Z, et al. ${ }^{68}$ Ga-PRGD2 PET/CT in the evaluation of Glioma: a prospective study. Mol Pharm. 2014; 11: 3923-9.

41. Iagaru A, Mosci C, Mittra E, Zaharchuk G, Fischbein N, Harsh G, et al Glioblastoma multiforme recurrence: An exploratory study of ${ }^{18}$ F-FPPRGD2 PET/CT. Radiology. 2015, in press. DOI: http://dx.doi.org/10.1148/radiol 2015141550.

42. Gaertner FC, Kessler H, Wester HJ, Schwaiger M, Beer AJ. Radiolabelled RGD peptides for imaging and therapy. Eur J Nucl Med Mol Imaging. 2012; 39 Suppl 1: S126-38.

43. Zhou Y, Chakraborty S, Liu S. Radiolabeled Cyclic RGD peptides as radiotracers for imaging tumors and thrombosis by SPECT. Theranostics. 2011; $1: 58-82$.

44. Brix G, Lechel U, Glatting G, Ziegler SI, Munzing W, Muller SP, et al. Radiation exposure of patients undergoing whole-body dual-modality ${ }^{18}$ F-FDG PET/CT examinations. J Nucl Med. 2005; 46: 608-13.

45. Huang B, Law MW, Khong PL. Whole-body PET/CT scanning: estimation of radiation dose and cancer risk. Radiology. 2009; 251: 166-74.

46. Beer AJ, Haubner R, Wolf I, Goebel M, Luderschmidt S, Niemeyer M, et al. PET-based human dosimetry of 18F-galacto-RGD, a new radiotracer for imaging av $\beta 3$ expression. J Nucl Med. 2006; 47: 763-9.

47. The 2007 Recommendations of the International Commission on Radiological Protection. ICRP publication 103. Annals of the ICRP. 2007; 37: 1-332.
48. Beer AJ, Haubner R, Sarbia M, Goebel M, Luderschmidt S, Grosu AL, et al. Positron emission tomography using [ $\left.{ }^{18} \mathrm{~F}\right]$ Galacto-RGD identifies the level of integrin av $\beta 3$ expression in man. Clin Cancer Res. 2006; 12: 3942-9.

49. Beer AJ, Grosu AL, Carlsen J, Kolk A, Sarbia M, Stangier I, et al. $\left[{ }^{18} \mathrm{~F}\right]$ galacto-RGD positron emission tomography for imaging of $\operatorname{av} \beta 3$ expression on the neovasculature in patients with squamous cell carcinoma of the head and neck. Clin Cancer Res. 2007; 13: 6610-6.

50. Beer AJ, Niemeyer M, Carlsen J, Sarbia M, Nahrig J, Watzlowik P, et al. Patterns of av $\beta 3$ expression in primary and metastatic human breast cancer as shown by ${ }^{18} \mathrm{~F}-G$ alacto-RGD PET. J Nucl Med. 2008; 49: 255-9.

51. Doss M, Kolb HC, Zhang JJ, Bélanger MJ, Stubbs JB, et al. Biodistribution and radiation dosimetry of the integrin marker ${ }^{18} \mathrm{~F}-\mathrm{RGD}-\mathrm{K} 5$ determined from whole-body PET/CT in monkeys and humans. J Nucl Med. 2012 May;53(5):787-95.

52. Mena E, Owenius R, Turkbey B, Sherry R, Bratslavsky G, Macholl S, et al. $\left[{ }^{18} \mathrm{~F}\right]$ fluciclatide in the in vivo evaluation of human melanoma and renal tumors expressing $\alpha v \beta 3$ and $a v \beta 5$ integrins. Eur J Nucl Med Mol Imaging. 2014; 41: 1879-88.

53. Beer AJ, Lorenzen S, Metz S, Herrmann K, Watzlowik P, Wester HJ, et al. Comparison of integrin av $\beta 3$ expression and glucose metabolism in primary and metastatic lesions in cancer patients: a PET study using ${ }^{18} \mathrm{~F}$-galacto-RGD and ${ }^{18 F-F D G . ~ J ~ N u c l ~ M e d . ~ 2008 ; ~ 49: ~ 22-9 . ~}$

54. Chen X, Tohme M, Park R, Hou Y, Bading JR, Conti PS. Micro-PET imaging of av $\beta 3$-integrin expression with ${ }^{18} \mathrm{~F}$-labeled dimeric RGD peptide. Mol Imaging. 2004; 3: 96-104.

55. Wu Y, Zhang X, Xiong Z, Cheng Z, Fisher DR, Liu S, et al. microPET imaging of glioma integrin av $\beta 3$ expression using ${ }^{64} \mathrm{Cu}$-labeled tetrameric RGD peptide. J Nucl Med. 2005; 46: 1707-18.

56. Zhang X, Xiong Z, Wu Y, Cai W, Tseng JR, Gambhir SS, et al. Quantitative PET imaging of tumor integrin $\alpha v \beta 3$ expression with ${ }^{18} \mathrm{~F}-\mathrm{FRGD} 2$. J Nucl Med. 2006; 47: 113-21.

57. Wu Z, Li ZB, Chen K, Cai W, He L, Chin FT, et al. microPET of tumor integrin av $\beta 3$ expression using ${ }^{18} \mathrm{~F}$-labeled PEGylated tetrameric RGD peptide ${ }^{18}$ F-FPRGD4). J Nucl Med. 2007; 48: 1536-44.

58. Li ZB, Cai W, Cao O, Chen K, Wu Z, He L, et al. ${ }^{64} \mathrm{Cu}$-labeled tetrameric and octameric RGD peptides for small-animal PET of tumor av $\beta 3$ integrin expression. J Nucl Med. 2007; 48: 1162-71.

59. Li ZB, Chen $\mathrm{K}$, Chen $\mathrm{X}$. ${ }^{68} \mathrm{Ga}$-labeled multimeric RGD peptides for microPET imaging of integrin av $\beta 3$ expression. Eur J Nucl Med Mol Imaging. 2008; 35: $1100-8$.

60. Thumshirn G, Hersel U, Goodman SL, Kessler H. Multimeric cyclic RGD peptides as potential tools for tumor targeting: solid-phase peptide synthesis and chemoselective oxime ligation. Chemistry. 2003; 9: 2717-25.

61. Poethko T, Schottelius M, Thumshirn G, Hersel U, Herz M, Henriksen G, et al. Two-step methodology for high-yield routine radiohalogenation of peptides: ${ }^{18 F-l a b e l e d ~ R G D ~ a n d ~ o c t r e o t i d e ~ a n a l o g s . ~ J ~ N u c l ~ M e d . ~ 2004 ; ~ 45: ~ 892-902 . ~}$

62. Boturyn D, Coll JL, Garanger E, Favrot MC, Dumy P. Template assembled cyclopeptides as multimeric system for integrin targeting and endocytosis. J Am Chem Soc. 2004; 126: 5730-9.

63. Liu Z, Liu S, Wang F, Liu S, Chen X. Noninvasive imaging of tumor integrin expression using ${ }^{18} \mathrm{~F}$-labeled RGD dimer peptide with $\mathrm{PEG}_{4}$ linkers. Eur J Nucl Med Mol Imaging. 2009; 36: 1296-307.

64. Chin FT, Shen B, Liu S, Berganos RA, Chang E, Mittra E, et al. First experience with clinical-grade $\left(\left[{ }^{18} \mathrm{~F}\right] \mathrm{FPPRGD} 2\right)$ : an automated multi-step radiosynthesis for clinical PET studies. Mol Imaging Biol. 2012; 14: 88-95.

65. Iagaru A, Mosci C, Shen B, Chin FT, Mittra E, Telli ML, et al. ${ }^{18}$ F-FPPRGD2 PET/CT: pilot phase evaluation of breast cancer patients. Radiology. 2014; 273: 549-59.

66. Mi B, Yu C, Pan D, Yang M, Wan W, Niu G, et al. Pilot Prospective Evaluation of ${ }^{18} \mathrm{~F}$-Alfatide II for detection of skeletal metastases, in comparison with ${ }^{18}$ F-FDG PET/CT. Theranostics. 2015; 5: 1115-1121.

67. Withofs N, Signolle N, Somja J, Lovinfosse P, Nzaramba EM, Mievis F, et al. ${ }^{18 F-F P R G D 2 ~ P E T / C T ~ i m a g i n g ~ o f ~ i n t e g r i n ~} \alpha v \beta 3$ in renal carcinomas: correlation with histopathology. J Nucl Med. 2015; 56: 361-4

68. Montet X, Montet-Abou K, Reynolds F, Weissleder R, Josephson L. Nanoparticle imaging of integrins on tumor cells. Neoplasia. 2006; 8: 214-22.

69. Yoon HJ, Kang KW, Chun IK, Cho N, Im SA, Jeong S, et al. Correlation of breast cancer subtypes, based on estrogen receptor, progesterone receptor, and HER2, with functional imaging parameters from ${ }^{68} \mathrm{Ga}-\mathrm{RGD}$ PET/CT and ${ }^{18 F-F D G ~ P E T / C T . ~ E u r ~ J ~ N u c l ~ M e d ~ M o l ~ I m a g i n g . ~ 2014 ; ~ 41: ~ 1534-43 . ~}$

70. Zhao Y, Bachelier R, Treilleux I, Pujuguet P, Peyruchaud O, Baron R, et al. Tumor av $\beta 3$ integrin is a therapeutic target for breast cancer bone metastases. Cancer Res. 2007; 67: 5821-30.

71. Khurana R, Simons M, Martin JF, Zachary IC. Role of angiogenesis in cardiovascular disease: a critical appraisal. Circulation. 2005; 112: 1813-24.

72. Giancotti FG, Ruoslahti E. Integrin signaling. Science. 1999; 285: 1028-32.

73. Makowski MR, Ebersberger U, Nekolla S, Schwaiger M. In vivo molecular imaging of angiogenesis, targeting $\alpha v \beta 3$ integrin expression, in a patient after acute myocardial infarction. Eur Heart J. 2008; 29: 2201.

74. Sun $Y$, Zeng Y, Zhu Y, Feng F, Xu W, Wu C, et al. Application of ${ }^{68} \mathrm{Ga}$-PRGD2 PET/CT for av $\beta 3$-integrin imaging of myocardial infarction and stroke. Theranostics. 2014; 4: 778-86.

75. Fukui M, Kono S, Sueishi K, Ikezaki K. Moyamoya disease. Neuropathology. 2000; 20 Suppl: S61-4. 
76. Kim SK, Wang KC, Kim DG, Paek SH, Chung HT, Han MH, et al. Clinical feature and outcome of pediatric cerebrovascular disease: a neurosurgical series. Childs Nerv Syst. 2000; 16: 421-8.

77. Baaj AA, Agazzi S, Sayed ZA, Toledo M, Spetzler RF, van Loveren H. Surgical management of moyamoya disease: a review. Neurosurg Focus. 2009; 26 : E7.

78. Kim YI, Phi JH, Paeng JC, Choi H, Kim SK, Lee YS, et al. In vivo evaluation of angiogenic activity and its correlation with efficacy of indirect revascularization surgery in pediatric moyamoya disease. J Nucl Med. 2014; 55: $1467-72$.

79. Ross R. Atherosclerosis--an inflammatory disease. N Engl J Med. 1999; 340: 115-26.

80. Libby P. Inflammation in atherosclerosis. Nature. 2002; 420: 868-74.

81. Virmani R, Kolodgie FD, Burke AP, Finn AV, Gold HK, Tulenko TN, et al. Atherosclerotic plaque progression and vulnerability to rupture: angiogenesis as a source of intraplaque hemorrhage. Arterioscler Thromb Vasc Biol. 2005; 25: 2054-61.

82. Hoshiga M, Alpers CE, Smith LL, Giachelli CM, Schwartz SM. av $\beta 3$ integrin expression in normal and atherosclerotic artery. Circ Res. 1995; 77: 1129-35.

83. Beer AJ, Pelisek J, Heider P, Saraste A, Reeps C, Metz S, et al. PET/CT imaging of integrin av $\beta 3$ expression in human carotid atherosclerosis. JACC Cardiovasc Imaging. 2014; 7: 178-87.

84. Zhu Z, Yin Y, Zheng K, Li F, Chen X, Zhang F, et al. Evaluation of synovial angiogenesis in patients with rheumatoid arthritis using ${ }^{68} \mathrm{Ga}-\mathrm{PRGD} 2$ PET/CT: a prospective proof-of-concept cohort study. Ann Rheum Dis. 2014; 73: 1269-72.

85. Petitclerc E, Stromblad S, von Schalscha TL, Mitjans F, Piulats J, Montgomery $\mathrm{AM}$, et al. Integrin av $\beta 3$ promotes M21 melanoma growth in human skin by regulating tumor cell survival. Cancer Res. 1999; 59: 2724-30.

86. Rolli M, Fransvea E, Pilch J, Saven A, Felding-Habermann B. Activated integrin av $\beta 3$ cooperates with metalloproteinase MMP-9 in regulating migration of metastatic breast cancer cells. Proc Natl Acad Sci U S A. 2003; 100: 9482-7.

87. Burke PA, DeNardo SJ, Miers LA, Lamborn KR, Matzku S, DeNardo GL. Cilengitide targeting of av $\beta 3$ integrin receptor synergizes with radioimmunotherapy to increase efficacy and apoptosis in breast cancer xenografts. Cancer Res. 2002; 62: 4263-72.

88. Yang M, Gao H, Yan Y, Sun X, Chen K, Quan Q, et al. PET imaging of early response to the tyrosine kinase inhibitor ZD4190. Eur J Nucl Med Mol Imaging. 2011; 38: 1237-47.

89. Battle MR, Goggi JL, Allen L, Barnett J, Morrison MS. Monitoring tumor response to antiangiogenic sunitinib therapy with ${ }^{18} \mathrm{~F}$-fluciclatide, an ${ }^{18} \mathrm{~F}-$-labeled av $\beta 3$-integrin and av $\beta 5$-integrin imaging agent. J Nucl Med. 2011; 52: 424-30.

90. Shi J, Jin Z, Liu X, Fan D, Sun $Y$, Zhao H, et al. PET imaging of neovascularization with ${ }^{68} \mathrm{Ga}-3 \mathrm{PRGD} 2$ for assessing tumor early response to Endostar antiangiogenic therapy. Mol Pharm. 2014; 11: 3915-22.

91. Terry SY, Abiraj K, Lok J, Gerrits D, Franssen GM, Oyen WJ, et al. Can ${ }^{111}$ In-RGD2 monitor response to therapy in head and neck tumor xenografts? J Nucl Med. 2014; 55: 1849-55.

92. Rylova SN, Barnucz E, Fani M, Braun F, Werner M, Lassmann S, et al. Does imaging av $\beta 3$ integrin expression with PET detect changes in angiogenesis during bevacizumab therapy? J Nucl Med. 2014; 55: 1878-84.

93. Higuchi T, Bengel FM, Seidl S, Watzlowik P, Kessler H, Hegenloh R, et al. Assessment of av $\beta 3$ integrin expression after myocardial infarction by positron emission tomography. Cardiovasc Res. 2008: 78: 395-403.

94. Verjans J, Wolters S, Laufer W, Schellings M, Lax M, Lovhaug D, et al. Early molecular imaging of interstitial changes in patients after myocardial infarction: comparison with delayed contrast-enhanced magnetic resonance imaging. J Nucl Cardiol. 2010; 17: 1065-72.

95. Choi H, Phi JH, Paeng JC, Kim SK, Lee YS, Jeong JM, et al. Imaging of integrin av $\beta 3$ expression using ${ }^{68} \mathrm{Ga}-\mathrm{RGD}$ positron emission tomography in pediatric cerebral infarct. Mol Imaging. 2013; 12: 213-7.

96. Pichler BJ, Kneilling M, Haubner R, Braumuller H, Schwaiger M, Rocken M, et al. Imaging of delayed-type hypersensitivity reaction by PET and 18F-galacto-RGD. J Nucl Med. 2005; 46: 184-9.

97. Guo N, Zhu Z, Zheng K, Xing H, Li F, Chen X, et al. Multi-bed-position dynamic imaging and kinetic analysis of 68Ga-NOTA-PRGD2 in lung cancer patients. J Nucl Med. 2012; 53(supplement 1): 1253-1253.

98. Guo N, Lang L, Gao H, Niu G, Kiesewetter DO, Xie $\mathrm{O}$ et al. Quantitative analysis and parametric imaging of ${ }^{18} \mathrm{~F}-$ labeled monomeric and dimeric RGD peptides using compartment model. Mol Imaging Biol. 2012; 14: 743-52.

99. Guo $\mathrm{N}$, Lang $\mathrm{L}, \mathrm{Li} \mathrm{W}$, Kiesewetter $\mathrm{DO}$, Gao $\mathrm{H}$, Niu G, et al. Quantitative analysis and comparison study of [ ${ }^{18}$ F]AlF-NOTA-PRGD2, [ ${ }^{18 F] F P P R G D 2 ~ a n d ~}$ [ $\left.{ }^{68} \mathrm{Ga}\right] \mathrm{Ga}-N O T A-P R G D 2$ using a reference tissue model. PloS One. 2012; 7: e37506.

100. Guo N, Zhang F, Zhang X, Guo J, Lang L, Kiesewetter DO, et al. Quantitative evaluation of tumor early response to a vascular-disrupting agent with dynamic PET. Mol Imaging Biol. 2015, in press. DOI 10.1007/s11307-015-0854-4.

101. Guo J, Guo N, Lang L, Kiesewetter DO, Xie Q, Li Q, et al. (18)F-alfatide II and ${ }^{18} \mathrm{~F}$-FDG dual-tracer dynamic PET for parametric, early prediction of tumor response to therapy. J Nucl Med. 2014; 55: 154-60.

102. Tomasi G, Kenny L, Mauri F, Turkheimer F, Aboagye EO. Quantification of receptor-ligand binding with $\left.{ }^{18} \mathrm{~F}\right]$ fluciclatide in metastatic breast cancer patients. Eur J Nucl Med Mol Imaging. 2011; 38: 2186-97. 